\title{
KULEUVEN
}

DEPARTMENT OF ECONOMICS

\section{Individual welfare analysis for collective households}

Laurens CHERCHYE, Sam COSAERT, Bram DE ROCK, Pieter Jan KERSTENS and Frederic VERMEULEN

FACULTY OF ECONOMICS AND BUSINESS

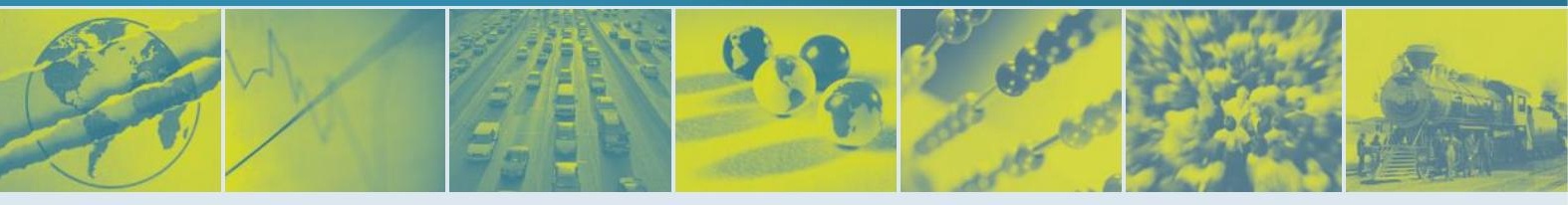

DISCUSSION PAPER SERIES DPS17.16

NOVEMBER 2017 


\title{
Individual welfare analysis for collective households
}

\author{
Laurens Cherchye* Sam Cosaert ${ }^{\dagger} \quad$ Bram De Rock ${ }^{\ddagger}$ \\ Pieter Jan Kerstens ${ }^{\S} \quad$ Frederic Vermeulen
}

November 17, 2017

\begin{abstract}
We propose novel tools for the analysis of individual welfare on the basis of aggregate household demand behavior. The method assumes a collective model of household consumption with the public and private nature of goods specified by the empirical analyst. A main distinguishing feature of our method is that it builds on a revealed preference characterization of the collective model that is intrinsically nonparametric. We show how to identify individual money metric welfare indices from observed household demand, along with the intrahousehold sharing rule and the individuals' willingness-to-pay for public consumption (i.e. Lindahl prices). The method is easy to use in practice and yields informative empirical results, which we demonstrate through a simulation analysis and an empirical application to labor supply data.
\end{abstract}

Keywords: individual welfare; collective model; revealed preferences; sharing rule; money metric welfare index; identification; labor supply.

JEL codes: D11, D12, D13, C14

*Department of Economics, University of Leuven (KU Leuven). E. Sabbelaan 53, B-8500 Kortrijk, Belgium. E-mail: laurens.cherchye@kuleuven.be. Laurens Cherchye gratefully acknowledges the European Research Council (ERC) for his Consolidator Grant 614221, the Research Fund KU Leuven and the FWO (Research Foundation Flanders).

${ }^{\dagger}$ Luxembourg Institute of Socio-Economic Research (LISER), Porte des Sciences 11, L-4366 Esch-surAlzette, Luxembourg. E-mail: sam.cosaert@liser.lu.

${ }^{\ddagger}$ ECARES, Université Libre de Bruxelles, and Department of Economics, University of Leuven (KU Leuven). Avenue F. D. Roosevelt 50, CP 114, B-1050 Brussels, Belgium. E-mail: bderock@ulb.ac.be. Bram De Rock gratefully acknowledges FWO and BELSPO for their financial support.

$\S$ Department of Food and Resource Economics (IFRO), University of Copenhagen. Rolighedsvej 23, DK-1958 Frederiksberg C, Denmark. E-mail: pjk@ifro.ku.dk.

IDepartment of Economics, University of Leuven (KU Leuven) and Universidad del Pacifico. Naamsestraat 69, B-3000 Leuven, Belgium. E-mail: frederic.vermeulen@kuleuven.be. Frederic Vermeulen gratefully acknowledges financial support from the FWO (Research Foundation Flanders). 


\section{Introduction}

The analysis of individual welfare is at the core of the applied welfare literature. It is relevant for a large variety of policy-relevant empirical questions. For example, when assessing inequality in a society, one of the basic objects of interest is the consumption level of individuals. If the within-household distribution of resources is highly unbalanced, inequality between individuals will be very different from inequality between aggregate households. In a similar spirit, it is individuals who have utilities and not households. This pleads for using measures of individual welfare when empirically evaluating the impact of policy reforms, such as tax reforms.

The empirical analysis of individual welfare raises two important challenges. Firstly, at the empirical level, the analyst usually only observes the aggregate household expenditures. The within-household sharing of resources is typically not observed. ${ }^{1}$ Secondly, at the conceptual level, an important issue relates to the fact that households are intrinsically characterized by public consumption, which simultaneously benefits the different household members. The question remains how to evaluate this public consumption in the context of individual welfare analysis. This paper presents a novel empirical method for the analysis of individual welfare that addresses both challenges. It is based on observed aggregate household consumption behavior, and it effectively accounts for intrahoushold public consumption in the evaluation of individual welfare.

We take as a starting point that the collective model of Apps and Rees (1988) and Chiappori $(1988,1992)$ provides a well-suited conceptual framework for dealing with these questions. ${ }^{2}$ The attractive feature of this model is that it explicitly recognizes that households are not unitary decision making units, but consist of multiple decision makers with own rational preferences. Observed household consumption is regarded as the outcome of a within-household interaction process. The model (only) assumes that this process leads to Pareto-efficient intrahousehold allocations. Such a non-unitary approach to modeling households' consumption behavior is particularly relevant for the analysis of individual welfare, as it naturally allows us to account for the possibility of an unequal distribution of resources and welfare within households. See, for example, Chiappori and Meghir (2014) and Chiappori (2016) for extensive argumentation.

A main distinguishing feature of our method is that it builds on a revealed preference characterization of the collective model that is intrinsically nonparametric (in the tradition of Afriat (1967), Diewert (1973) and Varian (1982)). The method does not require an

\footnotetext{
${ }^{1}$ In the past few years, more attention is given to the gathering of information on the consumption of individuals inside households (see, for example, Browning and Goertz (2012) and Cherchye, De Rock, and Vermeulen (2012)). Datasets with such information are still not widespread, though.

${ }^{2}$ The collective model has become a workhorse model in the family economics literature. It has been proven to be a viable alternative to the unitary model that is deficient when used in a context of multiperson decision making. See, for example, Browning and Chiappori (1998), Cherchye and Vermeulen (2008), Cherchye, De Rock, and Vermeulen (2007, 2009, 2011), and Attanazio and Lechene (2014).
} 
explicit parametric/functional specification of the intrahousehold decision process (e.g. individual preferences). This is particularly attractive from a conceptual point of view. From an empirical perspective, one potential disadvantage of this robust methodology is that the welfare-economic concepts will not be "point" identified but "set" identified (yielding lower and upper bounds on the individual welfare measures, as we explain in Sections 3 and 4). However, if the identified sets are tight (i.e. sharp upper and lower bounds), the practical relevance of this issue is low. Moreover, if the nonparametrically identified sets turn out to be wide, then this basically demonstrates that any more specific welfare-economic conclusion obtained from a parametric analysis is likely to depend heavily on the (nonverifiable) functional structure that is imposed.

We focus on a collective model with public and private consumption, in which the private and public nature of commodities is specified by the empirical analyst. We start from the revealed preference characterization of this model (Cherchye, De Rock, and Vermeulen, 2011), and we develop a method that can provide the empirical tools for analyzing the individual welfare questions described above. First, we show how to identify the intrahousehold sharing rule, which defines the within-household distribution of resources. ${ }^{3}$ Next, we build on this sharing rule identification to subsequently identify the individuals' money metric welfare indices, which define the income that individuals need to be equally well off (in utility terms) when single as in their current households. Chiappori and Meghir (2014) particularly advocated the use of these indices for individual welfare analysis based on the collective model in the presence of public goods. In our empirical application, we will show that our identification method can be combined with nonparametric (e.g. Nadaraya-Watson) as well as parametric (e.g. QUAIDS) demand estimation, and that the method is straightforward to use in practice. In addition, it will demonstrate that our method has substantial empirical bite, despite its nonparametric orientation.

At the methodological level, this paper complements recent work of Cherchye, De Rock, Lewbel, and Vermeulen (2015). Two main differences are that (1) this earlier paper focused on a general collective consumption model in which the (public or private) nature of the goods is left unspecified, and (2) the proposed method allows for sharing rule recovery but not for identification of money metric welfare indices. ${ }^{4}$ This last difference

\footnotetext{
${ }^{3}$ The sharing rule takes a central position in empirical applications of collective consumption models. See, for example, Browning, Bourguignon, Chiappori, and Lechene (1994), Chiappori, Fortin, and Lacroix (2002), Blundell, Chiappori, and Meghir (2005), Lewbel and Pendakur (2008), Bourguignon, Browning, and Chiappori (2009), Couprie, Peluso, and Trannoy (2010), Lise and Seitz (2011), Bargain and Donni (2012), Cherchye, De Rock, and Vermeulen (2012), Browning, Chiappori, and Lewbel (2013) and Dunbar, Lewbel, and Pendakur (2013) for various applications of the collective consumption model that make use of the sharing rule concept.

${ }^{4}$ Technically, as we will explain below, the identification of money metric welfare indices requires the recovery of individuals' shadow/Lindahl prices of publicly consumed quantities. This recovery is not possible by using Cherchye, De Rock, Lewbel, and Vermeulen (2015)'s method for sharing rule identification when the (public or private) nature of goods is unknown. As a direct implication, the
} 
directly motivates the relevance of our contribution in the current paper because, as indicated above, money metric welfare indices have been advocated as particularly useful for individual welfare analysis in a collective consumption context. Moreover, in empirical applications it is often possible to formulate reasonable assumptions regarding the nature of goods prior to the actual empirical analysis. For instance, this applies to the labor supply setting that we will use as our leading example throughout this paper.

We will demonstrate the practical usefulness of our method by means of a simulation exercise, as well as an empirical application to data drawn from the Panel Study of Income Dynamics (PSID). Our simulation exercise will illustrate the collective consumption mechanics underlying our identification method. Next, our empirical application is the first one that uses nonparametric revealed preference techniques to implement the collective money metric welfare concepts advocated by Chiappori and Meghir (2014) for observational household consumption data. Through various exercises, we will show that our method allows for an informative empirical analysis. For example, our results for the money metric welfare index enable us to quantify the households' economic gains through public consumption (i.e. scale economies), and to assess the effects of household income and relative wages on the intrahousehold (money metric) welfare distribution. In addition, we will show how to use our method to assess the prevalence of individual poverty, quantified in terms of both the sharing rule and money metric welfare indices.

The rest of this paper unfolds as follows. In the next section, we define our concept of rational household behavior in terms of the collective consumption model. Section 3 presents our method for sharing rule identification, and Section 4 shows how to subsequently identify individuals' money metric welfare indices. As we will explain, our revealed preference method leads to set identification (to be contrasted with the more standard notion of point identification), meaning that we recover upper and lower bounds on individual resource shares and money metric welfare indices. Section 5 presents our simulation analysis, and Section 6 our application to PSID data. Section 7 concludes.

\section{Collective rationality}

We assume a standard setting in which households consist of two decision makers, member 1 and member 2. The empirical analyst observes a set $N$ of household decision situations, which are characterized by aggregate consumption quantities, associated prices and incomes. In our following simulation and empirical application, the set $N$ will be drawn from the observed household demand function, which sets out the households' consumption quantities as a function of household level prices and incomes. Household consumption will be partly public and partly private. The public and private nature of

identification strategy that we develop in the current paper, which will allow us to recover individualspecific shadow prices, is substantively different from the one proposed by these authors. 
each good is specified prior to the empirical analysis.

To simplify the exposition, our following analysis will assume decision situations with the number of commodities limited to three: good 1 is private and assignable to household member 1 , good 2 is private and assignable to household member 2 , and good 3 is publicly consumed. As a specific example, we use the non-unitary labor supply setting with goods 1 and 2 the male's and female's leisure, and good 3 the remaining household consumption (measured as a Hicksian aggregate). The fact that we model the Hicksian aggregate consumption as public consumption allows it to be interpreted as purely public consumption or, alternatively, as private consumption associated with (positive) externalities.

This three-goods setting was studied by Chiappori $(1988,1992)$ in his original papers, and will also be considered in our following simulation and empirical application. At this point, we note that it is in principle possible to extend our following reasoning to settings with more commodities. In fact, it may well be that some private goods are not assignable to individual household members. However, in general we need that at least one good is assignable to each member.

Formally, let $l_{E}^{1}$ and $l_{E}^{2}$ denote the time spent on leisure by members 1 and 2 in household decision situation $E \in N$. Further, $Q_{E}$ is the amount of the public good in situation $E$. Finally, let $w_{E}^{1}$ and $w_{E}^{2}$ represent the individuals' wages (i.e. prices of leisure) and $y_{E}$ the household's total expenditures on leisure and consumption, i.e. $y_{E}=$ $w_{E}^{1} l_{E}^{1}+w_{E}^{2} l_{E}^{2}+Q_{E}$. Taken together, this defines the household data set

$$
S=\left\{\left(w_{E}^{1}, w_{E}^{2}, 1\right) ;\left(l_{E}^{1}, l_{E}^{2}, Q_{E}\right)\right\}_{E \in N} .
$$

We say that the data set $S$ is collectively rational if each decision situation $E \in N$ can be represented as Pareto efficient, which means that the household maximizes a weighted sum of individual utility functions subject to a budget constraint. ${ }^{5}$

Definition 1 Collective rationality. The household data set $S$ is collectively rational if there exist individual utility functions $U^{1}$ and $U^{2}$ and bargaining weights $\mu_{E}^{1}$ and $\mu_{E}^{2}$ such that, for all decision situations $E \in N$,

$$
\begin{gathered}
\left(l_{E}^{1}, l_{E}^{2}, Q_{E}\right)=\arg \max _{l^{1}, l^{2}, Q} \mu_{E}^{1} U^{1}\left(l^{1}, Q\right)+\mu_{E}^{2} U^{2}\left(l^{2}, Q\right) \\
\text { s.t. } \\
w_{E}^{1} l^{1}+w_{E}^{2} l^{2}+Q \leq w_{E}^{1} l_{E}^{1}+w_{E}^{2} l_{E}^{2}+Q_{E} .
\end{gathered}
$$

The Pareto weights $\mu_{E}^{1}$ and $\mu_{E}^{2}$ in the objective function represent the relative bargaining power of the household members 1 and 2. We remark that these bargaining

\footnotetext{
${ }^{5}$ Throughout, we follow Cherchye, De Rock, and Vermeulen (2011) by assuming that the individual utility functions $U^{1}$ and $U^{2}$ are continuous, monotone and concave.
} 
weights may vary depending on the decision situation $E$. Obviously, identifying these Pareto weights can give insight into the intrahousehold distribution of bargaining power. However, the value of these weights will strongly depend on the cardinalization of the utility functions $U^{1}$ and $U^{2}$.

An intrinsic feature of the collective model is the so-called sharing rule, which governs the within-household distribution of resources. This sharing rule is often interpreted as an alternative indicator of the relative bargaining power of individual household members. Unlike the Pareto weights $\mu_{E}^{1}$ and $\mu_{E}^{2}$, an attractive feature of the sharing rule is that it is expressed in monetary terms. Moreover, as argued in the Introduction, the sharing rule can be instrumental to addressing welfare questions that pertain to consumption inequality between individuals.

In what follows, an important focus will be on sharing rule identification. Therefore, it is useful to directly define collective rationality in terms of the sharing rule. To this end, we formally specify individual $i$ 's $(i=1,2)$ expenditure/consumption share as

$$
\eta_{E}^{i}=w_{E}^{i} l_{E}^{i}+\theta_{E}^{i} Q_{E}
$$

which comprises the individual's leisure component $w_{E}^{i} l_{E}^{i}$ and a share $\theta_{E}^{i}$ of the public consumption $Q_{E}$. The scalar $\theta_{E}^{i}$ gives individual $i$ 's shadow price for the public consumption, which intuitively corresponds to the individual's willingness-to-pay for this consumption.

Then, the Second Fundamental Theorem of Welfare Economics obtains the following equivalent definition of collective rationality.

Definition 2 Collective rationality: sharing rule representation. The household data set $S$ is collectively rational if there exist individual utility functions $U^{1}$ and $U^{2}$, expenditure shares $\eta_{E}^{1}$ and $\eta_{E}^{2}$ and shadow prices $\theta_{E}^{1}$ and $\theta_{E}^{2}$ such that, for all decision situations $E \in N$,

$$
\begin{gathered}
\left(l_{E}^{i}, Q_{E}\right)=\arg \max U^{i}\left(l^{i}, Q\right) \\
\text { s.t. } \\
w_{E}^{i} l^{i}+\theta_{E}^{i} Q \leq \eta_{E}^{i}
\end{gathered}
$$

with $\theta_{E}^{1}+\theta_{E}^{2}=1$.

This definition provides a "decentralized" expression of collective rationality. It shows that, for a given sharing rule (defining $\eta_{E}^{1}$ and $\eta_{E}^{2}$ ), collective rationality imposes individually rational (i.e. utility maximizing) behavior of each household member separately. Furthermore, the shadow prices $\theta_{E}^{1}$ and $\theta_{E}^{2}$ can be interpreted as Lindahl prices because Pareto efficiency requires these prices to sum to the price of the household's public consumption (i.e. $\theta_{E}^{1}+\theta_{E}^{2}=1$, for 1 equal to the price of the Hicksian public good). 


\section{Sharing rule recovery}

In this section, we start from Definition 2 of collective rationality to address identification of the individual shares $\eta_{E}^{1}$ and $\eta_{E}^{2}$ associated with an observed decision situation $E$. Basically, the method obtains recovery of these individual shares under the maintained assumption that the observed household consumption behavior satisfies collective rationality. In particular, we will show that we can define upper and lower bounds on the expenditure shares by starting from a nonparametric revealed preference characterization of the collective consumption model. The fact that we define bounds effectively obtains "set" identification (in contrast to "point" identification) of the household's sharing rule.

More specifically, our method recovers bounds on the shadow prices $\theta_{E}^{i}$, which directly implies bounds on $\eta_{E}^{i}\left(=w_{E}^{i} l_{E}^{i}+\theta_{E}^{i} Q_{E}\right)$. The method builds on the individual rationality requirement in Definition 2. The revealed preference characterization of this rationality condition will define inequality restrictions for observed demand behavior, which in turn will lead to set identification of $\theta_{E}^{i}$. By exploiting the revealed preference implications of collective rationality, we can shrink the region of member $i$ 's shadow prices in household $E$ from the trivial "uninformative" interval $[0,1]$ to an "informative" interval $\Theta_{E}^{i}=$ $\left[\theta_{E}^{i, l b}, \theta_{E}^{i, u b}\right]$ with $\theta_{E}^{i, l b} \geq 0$ and $\theta_{E}^{i, u b} \leq 1$.

As we will explain, our bounds will not necessarily represent the tightest bounds that can be obtained by exploiting all empirical restrictions implied by collective rationality. In the following, we let $\Phi_{E}^{i}$ represent these tightest bounds. We will define $\Theta_{E}^{i}$ such that $\Phi_{E}^{i} \subseteq \Theta_{E}^{i}$, i.e. $\Theta_{E}^{i}$ provides an empirical outer bound approximation of the theoretically tightest set $\Phi_{E}^{i}$. We will return to sharpness of our empirical bounds (defining $\Theta_{E}^{i}$ ) at the end of this section. Importantly, even though our bounds are not necessarily the tightest possible bounds in theory, they will have substantial empirical bite, as we will show in our simulation analysis in Section 5 and our application in Section 6. In addition, they will be very easy to compute in practice.

In what follows we will assume to have an arbitrarily large set $N$ of household consumption bundles with associated prices. For example, in our simulation exercise and empirical application in Sections 5 and 6, these bundles will be drawn from a household demand function $g$ that maps realizations of $w^{1}, w^{2}$ and $y$ on $\left(l^{1}, l^{2}, Q\right)=g\left(w^{1}, w^{2}, y\right)$. At this point, we remark that, in principle, we could also have expressed our following argument directly in terms of the continuous demand function $g$ rather than in terms of the discrete set $N$ (along the lines of Cherchye, De Rock, Lewbel, and Vermeulen (2015)). However, using the discrete set $N$ substantially facilitates our exposition. Moreover, as we will explain below, it implies a very simple enumeration method to obtain $\Theta_{E}^{i}$. Finally, it shows that our proposed method is also directly applicable to settings with discrete sets of household observations (as originally considered by Cherchye, De Rock, and Vermeulen (2011)). 
Individual (ir)rationality for given shadow prices. The basic idea is to exploit that violations of individual rationality imply violations of collective rationality. Thus, we have that the shadow price $\theta_{E}^{i}$ is not sustainable when it leads to a violation of individual rationality for individual $i$ in household $E$. In that case, we conclude that $\theta_{E}^{i} \notin \Phi_{E}^{i}$. In what follows, we characterize these unsustainable $\theta_{E}^{i}$ in revealed preference terms, and we will use this characterization to define the upper bound $\theta_{E}^{i, u b}$. Correspondingly, we can define the lower bound $\theta_{E}^{i, l b}=1-\theta_{E}^{j, u b}(j \neq i)$, by using the adding up condition $\theta_{E}^{1}+\theta_{E}^{2}=1$ for Lindahl prices.

More precisely, let us assume some given shadow prices $\theta_{E}^{1}$ and $\theta_{E}^{2}$. Then, Definition 2 simultaneously imposes individual rationality on both household members: there must exist utility functions $U^{1}$ and $U^{2}$ such that $\left(l_{E}^{1}, Q_{E}\right)$ maximizes $U^{1}$ and $\left(l_{E}^{2}, Q_{E}\right)$ maximizes $U^{2}$. Failure to find $U^{i}$ for at least one of the household members results in a rejection of collective rationality for the specified $\theta_{E}^{i}$, which means $\theta_{E}^{i} \notin \Phi_{E}^{i}$. We can rephrase this in revealed preference terms, by using that a necessary condition for individual rationality is that the data are consistent with the Weak Axiom of Revealed Preference (WARP). For our setting, WARP consistency of individual $i$ requires that, for all $n, n^{\prime} \in N$ such that $\left(l_{n}^{i}, Q_{n}\right) \neq\left(l_{n^{\prime}}^{i}, Q_{n^{\prime}}\right)$, there must exist shadow prices $\theta_{n}^{i}$ and $\theta_{n^{\prime}}^{i}$ that meet

$$
w_{n}^{i} l_{n}^{i}+\theta_{n}^{i} Q_{n} \geq w_{n}^{i} l_{n^{\prime}}^{i}+\theta_{n}^{i} Q_{n^{\prime}} \Rightarrow w_{n^{\prime}}^{i} l_{n}^{i}+\theta_{n^{\prime}}^{i} Q_{n}>w_{n^{\prime}}^{i} l_{n^{\prime}}^{i}+\theta_{n^{\prime}}^{i} Q_{n^{\prime}} .
$$

A sufficient condition for $\theta_{E}^{i}$ to be inconsistent with condition (1) is that, for some $n \in N$,

$$
\begin{gathered}
w_{E}^{i}\left(l_{n}^{i}-l_{E}^{i}\right)+\theta_{E}^{i}\left(Q_{n}-Q_{E}\right)<0 \text { and } \\
\forall \theta_{n}^{i} \in[0,1]: w_{n}^{i}\left(l_{E}^{i}-l_{n}^{i}\right)+\theta_{n}^{i}\left(Q_{E}-Q_{n}\right)<0 .
\end{gathered}
$$

If conditions (2) and (3) hold simultaneously, then we conclude that, for any specification of $\theta_{n}^{i}$, the WARP requirement (1) is violated for the given $\theta_{E}^{i}$. As a direct implication, we have that $\theta_{E}^{i} \notin \Phi_{E}^{i}{ }^{6}$

Finally, by replacing the second term on the right hand side of inequality (3) by its maximum and minimum potential values (i.e. zero and $\left(Q_{E}-Q_{n}\right)$ ), we obtain the two inequalities

$$
\begin{aligned}
w_{n}^{i}\left(l_{E}^{i}-l_{n}^{i}\right) & <0 \text { and } \\
w_{n}^{i}\left(l_{E}^{n}-l_{n}^{i}\right)+\left(Q_{E}-Q_{n}\right) & <0,
\end{aligned}
$$

which hold simultaneously if and only if (3) holds. This reformulation will be useful in

\footnotetext{
${ }^{6}$ We remark that we work with a strict inequality in condition (2). We do so because it facilitates the empirical implementation of our method. However, it also implies that, strictly speaking, we are not exhausting all empirical implications associated with the WARP condition in (1).
} 
practical applications, as it avoids having to implement the universal quantifier in (3) (for the unknown $\theta_{n}^{i}$ ).

Defining $\Theta_{E}^{i}=\left[\theta_{E}^{i, l b}, \theta_{E}^{i, u b}\right]$. Building on our above argument, we can define a linear program to compute the upper bound $\theta_{E}^{i, u b}$ and lower bound $\theta_{E}^{i, l b}$. Specifically, let $\delta$ be an arbitrarily small fixed number, then we need to solve

$$
\begin{aligned}
& \theta_{E}^{i, u b}=\min _{\theta} \theta-\delta \\
& \text { s.t. } \\
& w_{E}^{i}\left(l_{n}^{i}-l_{E}^{i}\right)+\theta\left(Q_{n}-Q_{E}\right)<0(\text { for all } n \in N) \\
& w_{n}^{i}\left(l_{E}^{i}-l_{n}^{i}\right)<0(\text { for all } n \in N) \\
& w_{n}^{i}\left(l_{E}^{i}-l_{n}^{i}\right)+\left(Q_{E}-Q_{n}\right)<0(\text { for all } n \in N) \\
& 0 \leq \theta \leq 1 .
\end{aligned}
$$

The intuition behind this program (which underlies our proof of Proposition 3) goes as follows. Suppose that all inequality constraints are satisfied for a given value of $\theta$, say $\bar{\theta}$. Our above explanation (of (2), (4) and (5)) implies that this shadow price specification $\bar{\theta}$ is inconsistent with the WARP condition (1). For the given $\bar{\theta}$, the second term on the left hand side of the first inequality constraint will be negative (because the second constraint implies $l_{E}^{i}<l_{n}^{i}$ ). But then it easily follows that all feasibility constraints are also satisfied for any $\theta>\bar{\theta}$, i.e. any $\theta>\bar{\theta}$ implies inconsistency with the WARP condition (1). From this reasoning, we can define a "most informative" (i.e. lowest) upper bound $\theta_{E}^{i, u b}$ on WARP-consistent shadow prices by seeking the lowest value of $\theta$ that satisfies the constraints of the above program. Finally, if the program is infeasible (i.e. an empty feasible region; e.g. because $l_{E}^{i}>l_{n}^{i}$ for all $\left.n \in N\right)$, then we conclude that we cannot find an informative upper bound. In that case, we set $\theta_{E}^{i, u b}$ equal to one.

We subtract $\delta$ in the objective of our minimization problem because the program recovers $\theta$ that do not sustain collective rationality (i.e. $\theta \notin \Phi_{E}^{i}$ ), whereas $\theta_{E}^{i, u b}$ defines an upper bound on the shadow prices that sustain collective rationality. In particular, the constraints of the problem guarantee consistency with (2), (4) and (5), which implies $\left(\theta_{E}^{i, u b}+\delta\right) \notin \Phi_{E}^{i}$. By solving a similar program, we can compute $\theta_{E}^{j, u b}$ for member $j \neq i$, which allows us to define the lower bound $\theta_{E}^{i, l b}=1-\theta_{E}^{j, u b}$. In turn, this obtains $\Theta_{E}^{i}=$ $\left[\theta_{E}^{i, l b}, \theta_{E}^{i, u b}\right]$.

We can now state our first main result. ${ }^{7}$

Proposition 3 We have that $\Phi_{E}^{i} \subseteq \Theta_{E}^{i}=\left[\theta_{E}^{i, l b}, \theta_{E}^{i, u b}\right]$.

As a final remark, because the set $N$ is discrete, $\theta_{E}^{i, u b}$ (and, thus, also $\theta_{E}^{i, l b}$ ) can be computed by simple enumeration: it suffices to check feasibility of the above program

\footnotetext{
${ }^{7}$ See Appendix A for the proofs of our main results.
} 
for each $n \in N$ separately, to subsequently define the minimum over all the feasible outcomes. This makes it very easy to define $\Theta_{E}^{i}$ in practical applications.

Sharpness. In general, we have $\Phi_{E}^{i} \subseteq \Theta_{E}^{i}$, which means that $\Theta_{E}^{i}$ need not necessarily exploit all the theoretical implications of collective rationality. One reason is that the computation of $\theta_{E}^{l b}$ and $\theta_{E}^{u b}$ is based on WARP, which only captures necessary implications of individually rational behavior. As shown by Houthakker (1950), utility maximization generally implies that the Strong Axiom of Revealed Preference (SARP) holds. SARP extends WARP by also exploiting transitivity of preferences. ${ }^{8}$ Our focus on WARP instead of SARP follows Cherchye, De Rock, Lewbel, and Vermeulen (2015). As argued by these authors, when exploiting SARP, it would be much more difficult, if not completely intractable, to fully operationalize transitivity in an empirical application. Moreover, in Sections 5 and 6 we will show that the WARP-based bounds produced by our methodology are informatively tight.

\section{Money metric welfare indices}

For a given decision situation $E$, the previous section proposed a method that set identifies individual income shares $\eta_{E}^{1}$ and $\eta_{E}^{2}$ by recovering sets of shadow prices $\Theta_{E}^{1}$ and $\Theta_{E}^{2}$ that are consistent with our assumption of collective rationality. We next show that we can use these bounds on the shadow prices $\theta_{E}^{i}$ for each individual $i$ to define informative upper and lower bounds on individuals' money metric welfare indices $(M M W I \mathrm{~s})$. As indicated in the Introduction, Chiappori and Meghir (2014) advocated the use of these $M M W I \mathrm{~s}$ for individual welfare analysis based on the collective model.

Intrinsically, money metric welfare indices are so-called Hicksian compensation measures. At the end of this section, we will define the associated Slutsky compensation concepts. In our following simulation exercise and empirical application, we will demonstrate the practical usefulness of comparing our estimates for individuals' (Hicksian) money metric welfare indices and the associated Slutsky compensation metrics.

Theoretical concept. In words, an individual's $M M W I$ computes the minimum income needed by household members to achieve the intrahousehold utility level (expressed in terms of material consumption) when the individual comes to live alone. Formally, for individual $i$ in the observed decision situation $E$ (with intrahousehold allocation

\footnotetext{
${ }^{8}$ The method to define bounds on individuals' money metric welfare indices that we introduce in Section 4 will also be based on WARP instead of SARP. In particular, our proofs of Propositions 4 and 5 will mainly use WARP-based revealed preference arguments (see Appendix A). See also Smeulders, Cherchye, De Rock, Spieksma, and Talla Nobibon (2015) who study the relationship between WARP and SARP for the labor supply setting on which we focus here.
} 
$\left.\left(l_{E}^{1}, l_{E}^{2}, Q_{E}\right)\right)$, we have

$$
M M W I_{E}^{i}=\min _{l^{i}, Q}\left\{w_{E}^{i} l^{i}+Q \mid\left(l^{i}, Q\right) \in B^{i}\left(l_{E}^{i}, Q_{E}\right)\right\}
$$

where $B^{i}\left(l_{E}^{i}, Q_{E}\right)$ represents the better-than-set associated with the given bundle $\left(l_{E}^{i}, Q_{E}\right)$, i.e.

$$
B^{i}\left(l_{E}^{i}, Q_{E}\right)=\left\{\left(l^{i}, Q\right) \mid U^{i}\left(l^{i}, Q\right) \geq U^{i}\left(l_{E}^{i}, Q_{E}\right)\right\} .
$$

Basically, this $M M W I_{E}^{i}$ calculates the minimal expenditures over the bundles that are at least as good as the bundle $\left(l_{E}^{i}, Q_{E}\right)$. In doing so, it accounts for the fact that, when becoming single, the individual will have to bear the full cost (and no longer the individual's shadow cost $\theta_{E}^{i}$ ) for the publicly consumed good. For our set-up, the single's price for the (Hicksian) public good equals 1, which will usually be above the shadow price $\theta_{E}^{i}$ that applies to the given household situation.

Finally, we remark that obviously $\left(l_{E}^{i}, Q_{E}\right) \in B^{i}\left(l_{E}^{i}, Q_{E}\right)$ and, by construction, the individual cannot face a price decrease of the Hicksian good when becoming single (because $\left.\theta_{E}^{i} \leq 1\right)$. Therefore, to compute $M M W I_{E}^{i}$ it suffices to only consider bundles $\left(l^{i}, Q\right)$ with $Q \leq Q_{E}$. We can use this in our following reasoning, by restricting attention to bundles with lower quantities of the more expensive Hicksian good when moving from a two-person household situation to single status.

Upper bound on $M M W I_{E}^{i}$. To define an informative upper bound on $M M W I_{E}^{i}$ we make use of the theoretical restrictions of collective rationality. The construction of the upper bound $m_{E}^{i, u b}$ requires an empirical inner bound approximation $I B^{i}\left(l_{E}^{i}, Q_{E}\right)$ of the unknown better-than-set $B^{i}\left(l_{E}^{i}, Q_{E}\right)$. This use of an inner bound set $I B^{i}\left(l_{E}^{i}, Q_{E}\right)$ to define an upper bound for $M M W I_{E}^{i}$ parallels Varian (1982)'s procedure to compute bounds on money metric utilities in a unitary household consumption context. The same remark applies to the outer bound approximation $O B^{i}\left(l_{E}^{i}, Q_{E}\right)$ that we will use to define a lower bound for $M M W I_{E}^{i}$. Basically, our method provides a collective version of Varian's original method.

Our construction of the empirical inner bound $I B^{i}\left(l_{E}^{i}, Q_{E}\right)$ makes use of the upper bound $\theta_{n}^{i, u b}$ on the shadow prices. More specifically, we define

$$
I B^{i}\left(l_{E}^{i}, Q_{E}\right)=\left\{\left(l_{n}^{i}, Q_{n}\right) \mid n \in N, Q_{n} \leq Q_{E} \text { and } w_{n}^{i}\left(l_{n}^{i}-l_{E}^{i}\right)+\theta_{n}^{i, u b}\left(Q_{n}-Q_{E}\right) \geq 0\right\} .
$$

In words, because we use the upper bound on the shadow prices that sustain collective rationality, we can always conclude that $\left(l_{n}^{i}, Q_{n}\right)$ is revealed preferred over $\left(l_{E}^{i}, Q_{E}\right)$ if $w_{n}^{i}\left(l_{n}^{i}-l_{E}^{i}\right)+\theta_{n}^{i, u b}\left(Q_{n}-Q_{E}\right) \geq 0$. By construction, the last inequality will also be satisfied for the true (but unobserved) shadow price (which is situated below $\theta_{n}^{i, u b}$ ). Thus, we obtain $\left(l_{n}^{i}, Q_{n}\right) \in B^{i}\left(l_{E}^{i}, Q_{E}\right)$ as soon as $w_{n}^{i}\left(l_{n}^{i}-l_{E}^{i}\right)+\theta_{n}^{i, u b}\left(Q_{n}-Q_{E}\right) \geq 0$. This is 
formally stated in the next proposition.

Proposition 4 We have that I $B^{i}\left(l_{E}^{i}, Q_{E}\right) \subseteq B^{i}\left(l_{E}^{i}, Q_{E}\right)$.

Based on Proposition 4, we can then define the upper bound

$$
m_{E}^{i, u b}=\min _{n}\left\{w_{E}^{i} l_{n}+Q_{n} \mid\left(l_{n}^{i}, Q_{n}\right) \in I B^{i}\left(l_{E}^{i}, Q_{E}\right)\right\} .
$$

Note that a simple enumeration procedure can be used to compute $I B^{i}\left(l_{E}^{i}, Q_{E}\right)$ and correspondingly $m_{E}^{i, u b}$. This is attractive from an empirical point of view.

Lower bound on $M M W I_{E}^{i}$. The construction of the empirical outer bound $O B^{i}\left(l_{E}^{i}, Q_{E}\right)$ is slightly more complicated and makes use of the lower bound $\theta_{n}^{i, l b}$ and upper bound $\theta_{n}^{i, u b}$ on the shadow prices. More specifically, we define

$$
\begin{aligned}
O B^{i}\left(l_{E}^{i}, Q_{E}\right)= & \left\{\left(l^{i}, Q\right) \mid w_{n}^{i}\left(l_{n}^{i}-l^{i}\right)+\theta_{n}^{i, l b}\left(Q_{n}-Q\right) \leq 0 \text { for all } n \in N\right. \text { for which } \\
& w_{E}^{i}\left(l_{E}^{i}-l_{n}^{i}\right)+\theta_{E}^{i, l b}\left(Q_{E}-Q_{n}\right) \geq 0 \text { if } Q_{n}<Q_{E} \text { or } \\
& \left.w_{E}^{i}\left(l_{E}^{i}-l_{n}^{i}\right)+\theta_{E}^{i, u b}\left(Q_{E}-Q_{n}\right) \geq 0 \text { if } Q_{n} \geq Q_{E}\right\} .
\end{aligned}
$$

The last two inequality constraints ensure that, for a given $n$, we can always conclude that $\left(l_{E}^{i}, Q_{E}\right)$ is revealed preferred over $\left(l_{n}^{i}, Q_{n}\right)$, while the first inequality constraint implies that we can never conclude that $\left(l_{n}^{i}, Q_{n}\right)$ is strictly revealed preferred over $\left(l^{i}, Q\right)$. Together this implies that we cannot conclude that $\left(l_{E}^{i}, Q_{E}\right)$ is strictly revealed preferred over $\left(l^{i}, Q\right)$. As a direct consequence, we cannot exclude $\left(l^{i}, Q\right)$ from $B^{i}\left(l_{E}^{i}, Q_{E}\right)$. This yields the following result.

Proposition 5 We have that $\left\{\left(l^{i}, Q\right) \in B^{i}\left(l_{E}^{i}, Q_{E}\right) \mid Q \leq Q_{E}\right\} \subseteq O B^{i}\left(l_{E}^{i}, Q_{E}\right)$.

From this proposition, we can define the lower bound

$$
m_{E}^{i, l b}=\min _{l^{i}, Q}\left\{w_{E}^{i} l^{i}+Q \mid\left(l^{i}, Q\right) \in O B^{i}\left(l_{E}^{i}, Q_{E}\right)\right\}
$$

Similar to before, it is straightforward to compute this lower bound through enumeration. In this case, it suffices to solve a simple linear program for each $n \in N$ that satisfies one of the last two inequality restrictions in our definition of $O B^{i}\left(l_{E}^{i}, Q_{E}\right)$.

Hicksian versus Slutsky compensations. The money metric welfare indices that we defined above are so-called Hicksian compensation measures. These measures account for the fact that individuals will adjust their behavior to changing prices (i.e. from Lindahl prices to a price of unity for the public consumption). These behavioral adjustments depend on the individuals' preferences, which are represented by the utility functions $U^{i}$. 
In the following sections, we will compare our estimates for these Hicksian compensation measures (i.e. the bounds $m_{E}^{i, l b}$ and $m_{E}^{i, u b}$ ) with the associated Slutsky compensation measures, which ignore behavioral reactions to price changes. These measures are defined as

$$
s_{E}^{i}=w_{E}^{i} l_{E}^{i}+Q_{E}
$$

Implicitly, Slutsky compensation measures assume that individuals $i$ do not adjust their consumption (defining the bundle $\left(l_{E}^{i}, Q_{E}\right)$ ) to the changing prices. Naturally, this implies $s_{E}^{i} \geq M M W I_{E}^{i}$, which reflects the well-known property that Slutsky compensations bound Hicksian compensations by construction. In our application in Section 6 , by comparing our (bound) estimates for the money metric welfare indices with the associated Slutsky compensation measures $s_{E}^{i}$, we will obtain insight into the empirical relevance of accounting for individual behavioral reactions to price changes.

\section{Simulation analysis}

To investigate the empirical performance of our revealed preference method, we begin by conducting a simulation analysis. This simulation exercise serves to illustrate the intrahousehold collective consumption mechanics that underlie our identification method, which will also facilitate the interpretation of our empirical results in Section 6. To do so, we will assume a fairly unsophisticated parametric specification of the individual preferences and the bargaining process. We will consider the tightness of the bounds that our method recovers for the within-household consumption sharing pattern (i.e. the individuals' shadow/Lindahl prices and associated expenditure shares) and for the individuals' money metric welfare indices. Attractively, we will conclude that, even for our nonsophisticated parametric setting, our method generates bounds that are close to the true individual shares $\eta_{E}^{i}$, Lindahl prices $\theta_{E}^{i}$ and welfare indices $M M W I_{E}^{i}$.

Set-up. Following our theoretical exposition, we assume a setting with three commodities, i.e. (private and assignable) leisure of the two spouses and remaining (public) Hicksian consumption. The individuals' utility functions take the Cobb-Douglas form

$$
\begin{aligned}
& U^{1}\left(l^{1}, Q\right)=\alpha \ln l^{1}+(1-\alpha) \ln Q, \\
& U^{2}\left(l^{2}, Q\right)=\beta \ln l^{2}+(1-\beta) \ln Q .
\end{aligned}
$$

In this simple specification, the parameters $0 \leq \alpha, \beta \leq 1$ define the individuals' preferences over private and public consumption. Generally, higher values for $\alpha$ and $\beta$ reflect stronger individual preferences for leisure. In what follows, we will use $\alpha=1 / 2$ and $\beta=1 / 4$, meaning that household member 2 has stronger preferences for public 
consumption than household member 1 .

As explained in Section 2, collective rationality means that the household consumption bundle $\left(l_{E}^{1}, l_{E}^{2}, Q_{E}\right)$ maximizes a weighted sum of the individual utility functions (i.e. $\left.\mu_{E}^{1} U^{1}+\mu_{E}^{2} U^{2}\right)$ subject to the household budget constraint. Here, we will assume that individual bargaining weights depend on the individual wages (as prices of leisure), by using $\mu_{E}^{1}=1$ and

$$
\mu_{E}^{2}=\frac{3}{2} \frac{w_{E}^{2}}{w_{E}^{1}}
$$

The intuition is straightforward: the higher the individual's wage, the stronger his or her bargaining position. This positive relationship between an individual's relative wage and his/her bargaining weight has broad empirical support in the literature on collective consumption models. See, for example, Browning, Chiappori, and Weiss (2014) for a recent review.

In what follows, we will specifically focus on a household decision situation $E$ with aggregate income $y_{E}=19.5$ and wages $w_{E}^{1}=0.25$ and $w_{E}^{2}=0.5$. This corresponds to a bargaining weight $\mu_{E}^{2}=3$, indicating that household member 2 has a stronger bargaining position than member 1 .

Intrahousehold sharing. For the given parametric specification and budget conditions, we can directly define the individuals' "true" Lindahl prices $\theta_{E}^{i}$ and expenditure shares $\eta_{E}^{i}$. In our case, we obtain

$$
\theta_{E}^{1}=0.182, \theta_{E}^{2}=0.818, \eta_{E}^{1}=4.875 \text { and } \eta_{E}^{2}=14.625
$$

corresponding to a household consumption bundle $\left(l_{E}^{1}, l_{E}^{2}, Q_{E}\right)=(9.750,7.315,13.406)$. The fact that member 1 contributes less to the public good than member 2 is not surprising, given that this individual has a weaker preference for public consumption. Next, the higher expenditure share of individual 2 reflects his/her better bargaining position.

Let us then investigate how well the bounds obtained through our empirical method (outlined in Section 2) approximate the above theoretical values for $\theta_{E}^{i}$ and $\eta_{E}^{i}$. In particular, we focus on tightness of the sets $\Theta_{E}^{i}=\left[\theta_{E}^{i, l b}, \theta_{E}^{i, u b}\right]$. As explained in Section 2, tight bounds for $\theta_{E}^{i}$ directly translate into similarly tight bounds for $\eta_{E}^{i}$.

To apply our identification procedure, we simulate a large set $N$ of bundles $\left(l^{1}, l^{2}, Q\right)$ that are collectively rational (for the given utilities and bargaining weights) under alternative regimes of the wages $w^{1}, w^{2}$ and income $y .{ }^{9}$ This resulted in the following

\footnotetext{
${ }^{9}$ Specifically, our following identification results for individuals' income shares, Lindahl prices and money metric welfare indices are based on $|N|=8000$. Details on our procedure to draw wages $w^{1}, w^{2}$ and incomes $y$ are available upon request. As explained in Sections 3 and 4, our identification methods require simple (enumeration) procedures, which makes it easy to consider large $|N|$.
} 
bounds

$$
\Theta_{E}^{1}=[0.171,0.200] \text { and } \Theta_{E}^{2}=[0.800,0.830]
$$

As a first observation, we note that these sets effectively contain the true values $\theta_{E}^{1}=0.182$ and $\theta_{E}^{2}=0.818$, which empirically confirms our theoretical result in Proposition 3. Next, and more interestingly, we observe that the bounds are very tight, which obtains fairly precise set identification. This shows that our recovery method can allow for a significantly informative analysis of the within-household distribution of individuals' resources. Our empirical application in the next section will show that this attractive feature also holds in real-life settings.

Money metric welfare. We next turn to identification of the individuals' money metric welfare indices $M M W I_{E}^{i}$. As a preliminary step, we again compute the "true" values of these indices for our parametric specification and the given prices and household income. In this application, these indices capture the income that individuals would need as singles (for the wages $\left(w_{E}^{1}, w_{E}^{2}\right)=(0.25,0.50)$ ) to be equally well off as in the household allocation $\left(l_{E}^{1}, l_{E}^{2}, Q_{E}\right)=(9.750,7.315,13.406)$. For our specification of the utility functions $U^{1}$ and $U^{2}$, we get

$$
M M W I_{E}^{1}=11.433 \text { and } M M W I_{E}^{2}=17.000,
$$

We observe that the sum of $M M W I_{E}^{1}$ and $M M W I_{E}^{2}$ clearly exceeds the household income 19.5. Following Chiappori and Meghir (2014), this indicates gains from publicness of $Q$ (and, thus, scale economies following from living together). In addition, we find that $M M W I_{E}^{2}>M M W I_{E}^{1}$, suggesting a higher welfare of the more powerful individual 2. At this point, however, we must also emphasize that this kind of conclusions should be taken with sufficient caution. In particular, for different reference prices, one may well obtain a reverse ordering of the individual money metric welfare indices (see Chiappori and Meghir (2014) for more discussion and a graphical example). Finally, we note that, for the given reference prices, the difference between the individuals' $M M W I \mathrm{~s}$ is less pronounced than between the income shares $\eta_{E}^{1}$ and $\eta_{E}^{2}$. This reflects the fact that household member 1 "benefits" from member 2's strong willingness to pay for the public consumption $Q_{E}$ in the situation where the two individuals form a household.

By using the information contained by the Lindahl price sets $\Theta_{n}^{1}$ and $\Theta_{n}^{2}$ for the bundles $n \in N$, we can use the procedures presented in Section 4 to identify the upper bound $m_{E}^{i, u b}$ and lower bound $m_{E}^{i, l b}$. For our current application, this yields

$$
\begin{gathered}
m_{E}^{1, l b}=8.050 \text { and } m_{E}^{1, u b}=13.681 \\
m_{E}^{2, l b}=16.750 \text { and } m_{E}^{2, u b}=17.036 .
\end{gathered}
$$


Like before, we observe that the bounds [8.050,13.681] and [16.750,17.036] contain the true index values 11.433 and 17.000. Again, this confirms our theoretical results in Propositions 4 and 5. Next, our bounds are tight, in particular for individual 2. Intuitively, a higher bargaining weight combined with stronger preferences for public consumption, implies that the observed household behavior reveals more information on individual 2's preferences for the public good. In turn, this leads to tighter money metric bounds for this individual.

Importantly, our nonparametric bounds are also informatively tight. For example, they accurately reveal the household's gains from public consumption. As indicated above, we can identify these scale economies by comparing the sum $M M W I_{E}^{1}+M M W I_{E}^{2}$ to the household expenditures $y$. In our case, even when we use the "conservative" lower bound estimates for the money welfare indices, we find a fairly large difference between $m_{E}^{1, l b}+m_{E}^{2, l b}(=24.8)$ and the household income $y(=19.5)$, thus revealing substantial economies of scale associated with living together. Next, our bounds also correctly recover that member 2 achieves a higher money metric welfare than member 1 for the chosen reference prices: the sets $[8.050,13.681]$ and $[16.745,17.036]$ do not overlap, which means that the difference between $M M W I_{E}^{1}$ and $M M W I_{E}^{2}$ is clearly identified.

As a final exercise, we compare our estimates of the individuals' money metric welfare indices with the corresponding Slutsky compensation measures $s_{E}^{i}=w_{E}^{i} l_{E}^{i}+Q_{E}$. For the given set-up, we obtain

$$
s_{E}^{1}=15.843 \text { and } s_{E}^{2}=17.063 \text {. }
$$

As explained at the end of Section 4, the indices $M M W I_{E}^{1}$ and $M M W I_{E}^{2}$ can be interpreted as Hicksian compensation concepts, which differ from the Slutsky concepts $s_{E}^{i}$ by effectively accounting for behavioral reactions associated with changing prices for public consumption in different living arrangements (i.e the individual's Lindahl price when living together versus a price of unity when living alone). We observe that our Hicksian estimates $\left(m_{E}^{i, u b}\right.$ and $\left.m_{E}^{i, l b}\right)$ are below the Slutsky measures, which shows the relevance of accounting for these behavioral reactions. The difference is most pronounced for household member 1 . This reflects that the Lindahl price for this member (with bounds $\theta_{E}^{i, l b}=0.171$ and $\left.\theta_{E}^{i, u b}=0.200\right)$ is substantially below the price of unity for public consumption when living alone. Intuitively, this relates to the interpretation of these Lindahl prices as indicating the individuals' preferences (i.e. willingness-to-pay) for the intrahousehold public consumption. 


\section{Empirical application}

We show the practical usefulness of our method through an empirical application to data drawn from the 1999-2009 Panel Study of Income Dynamics (PSID). In particular, we consider the sample of 865 two-person households without children that was also studied by Cherchye, De Rock, Lewbel, and Vermeulen (2015). In their original set-up, these authors distinguished between food, housing and other non-leisure expenditures. In line with our exposition in the previous sections, we treat all non-leisure consumption as a Hicksian (public) good.

Table 1 provides summary statistics on the relevant data for the sample at hand. Wages are net hourly wages. Leisure and annual hours worked are measured in hours per year. Full income and consumption expenditures are measured in nominal dollars per year. We refer to Cherchye, De Rock, Lewbel, and Vermeulen (2015) for additional details on the data construction method and sample selection procedure.

\begin{tabular}{|l|rrrr|}
\hline & Mean & Std. Dev. & Min & Max \\
\hline Male wage & 28.43 & 18.82 & 3.43 & 140.77 \\
Female wage & 22.61 & 14.26 & 3.13 & 113.90 \\
Male leisure & $3,611.48$ & 503.11 & 327.00 & $5,537.00$ \\
Female leisure & $4,109.21$ & 502.83 & $2,077.60$ & $5,771.20$ \\
Male annual hours worked & $2,212.52$ & 503.11 & 287.00 & $5,497.00$ \\
Female annual hours worked & $1,714.79$ & 502.83 & 52.80 & $3,746.40$ \\
Expenditure on male leisure & $103,502.04$ & $72,549.92$ & $3,569.24$ & $567,204.85$ \\
Expenditure on female leisure & $92,913.55$ & $62,828.74$ & $15,200.00$ & $612,561.46$ \\
Expenditure on Hicksian good & $39,463.99$ & $24,404.09$ & $8,200.00$ & $183,716.00$ \\
Full income & $235,879.59$ & $117,467.87$ & $75,620.37$ & $716,813.60$ \\
\hline
\end{tabular}

Table 1: Summary statistics

To apply our method, we first estimate the household demand function $g$, which maps combinations of $w^{1}, w^{2}$ and $y$ on $\left(l^{1}, l^{2}, Q\right)=g\left(w^{1}, w^{2}, y\right)$. In our following analysis, we will consider a fully nonparametric system. The nonparametric regressions we use are Nadaraya-Watson kernel estimators with a (Gaussian) radial basis function kernel. This is a special case of the local polynomial estimator, for which it is known that the residuals are asymptotically normally distributed under certain regularity conditions (Fan and Gijbels, 1996). To operationalize the methods that we outlined in Sections 3 and 4 , we draw a set $N$ of demand bundles from the estimated demand. In the following application, we use $|N|=400,000 .^{10}$

To show the versatility of our method, in Appendix B we also discuss the results for a flexible parametric demand system. In particular, we consider Banks, Blundell, and Lewbel (1997)'s Quadratic Almost Ideal Demand System (QUAIDS). We show that,

\footnotetext{
${ }^{10}$ More details on our drawing procedure are available upon request.
} 
for our application, the nonparametric kernel-based results are close to the QUAIDSbased results. Given this close similarity between the nonparametric and parametric bounds, our following exposition will solely consider results that are based on the kernel estimation. An attractive feature of such a fully nonparametric analysis is that the empirical conclusions are very robust to functional specification error.

As a final note, while our following analysis uses estimated household demand functions, we will not explicitly take into account estimation errors. Recent research has focused on inference for set identified objects. In particular, the studies of Kitamura and Stoye (2013), Henry and Mourifié (2013), Hoderlein and Stoye (2014) and Kaido, Molinari, and Stoye (2016) focus on set identification in a revealed preference context, and provide machinery that might be used for developing inference tools for our methodology. However, applying these techniques to our setting is quite a bit more complicated than existing applications to which such asymptotic theory has been successfully applied. Similar issues arise in other applications that combine demand estimation with revealed preference restrictions, such as Blundell, Browning, and Crawford (2008), Blundell, Kristensen, and Matzkin (2014) and Cherchye, De Rock, Lewbel, and Vermeulen (2015).

Sharing rule identification. As a first step, we compare our estimated upper and lower bounds for the individual income shares with so-called naive bounds. To construct these naive bounds, we exploit that leisure is private and assignable, so the value of a household member's leisure is a lower bound on that member's share of full income. This naive lower bound assigns all of the household's non-leisure consumption to the other household member. Similarly, a naive upper bound gives a household member his/her leisure and all of the household's non-leisure consumption. These naive bounds do not make use of any revealed preference restrictions associated with the collective household model. Comparing our revealed preference bounds with these naive bounds will provide insight into the identifying power of our identification method.

The results of this comparison are summarized in Table 2, which reports on the percentage point differences between upper and lower bounds on female expenditure shares for our sample of households. Since the individual shares sum up to one, the differences between the bounds are the same for men. Figure 4 in Appendix B gives an overview of the sharing rule results for our full sample of households. Comparing the naive bounds with the kernel-based bounds shows that our revealed preference based method provides a substantial improvement over the naive bounds, even with fully nonparametric demand function estimates. The average difference between the upper and lower naive bounds is about 17.52 percentage points, which narrows to 12.37 percentage points using the nonparametric estimates.

Interestingly, the bounds that we obtain are also informatively tight, which we illustrate in Table 3. This table reports on the distribution of the bounds for males and 
females in our sample, by showing percentiles of the upper and lower bounds on individuals' expenditure shares. Generally, we find that male and female resource shares are increasing with income. Actually, this could have been expected. It indicates that both male and female consumption are normal goods in the household. Next, we also find that male shares are generally somewhat above the female shares. This reveals that households are frequently characterized by unequal resource sharing, which turns out to be mainly disadvantageous for females.

\begin{tabular}{|l|cc|}
\hline & naive bounds & kernel-based bounds \\
\hline mean & 17.52 & 12.37 \\
minimum & 3.28 & 2.53 \\
1st quartile & 12.12 & 8.72 \\
median & 15.78 & 11.20 \\
3rd quartile & 21.68 & 15.23 \\
maximum & 64.03 & 39.18 \\
& & \\
nr. obs. & 865 & 865 \\
\hline
\end{tabular}

Table 2: Percentage point differences between upper and lower bounds on individual female expenditure shares

\begin{tabular}{|l|cc|cc|}
\hline & \multicolumn{2}{|c|}{ men } & \multicolumn{2}{c|}{ women } \\
\hline percentile & lower bound & upper bound & lower bound & upper bound \\
\hline 10 & $44,164.1$ & $62,357.1$ & $37,762.5$ & 56,460 \\
20 & $57,650.8$ & $77,453.9$ & $51,661.7$ & $69,787.1$ \\
30 & $69,100.9$ & $90,366.2$ & $60,266.8$ & $80,947.2$ \\
40 & $78,354.6$ & 99,948 & $69,939.2$ & $92,845.2$ \\
50 & $88,799.1$ & 114,435 & $82,624.6$ & 109,464 \\
60 & 103,382 & 130,149 & $94,371.4$ & 121,275 \\
70 & 120,469 & 152,908 & 107,762 & 139,339 \\
80 & 148,955 & 183,500 & 134,420 & 172,288 \\
90 & 195,878 & 244,181 & 172,784 & 221,761 \\
\hline
\end{tabular}

Table 3: Sharing rule bounds

Recovery of money metric welfare indices. As argued in the Introduction, a specific advantage of our method over the method of Cherchye, De Rock, Lewbel, and Vermeulen (2015) is that we can identify individuals' money metric welfare indices. These indices are particularly well-suited for individual welfare analysis in the context of the collective consumption model. We refer to Chiappori and Meghir (2014) for an in-depth discussion.

Table 4 gives a summary of the bounds that we obtain for our sample of households. Some interesting observations emerge from comparing the results in this table with the 
sharing rule results in Table 3. First, we find that the difference between the upper and lower bounds is generally close (and often tighter) in magnitude for the individual money metric indices than for the individual income shares. This shows that our method yields equally informative bounds for these two types of measures, which capture alternative dimensions of within-household inequality in consumption and welfare.

Next, although there is quite some overlap between the intervals, we observe that the bounds on the money metric indices are generally higher than for the individual resource shares (for both males and females). This indicates the cost of becoming single associated with the loss of public consumption (i.e., in a couple, public consumption is associated with individual Lindahl prices, whereas singles have to pay the (higher) market price for public consumption). Like for the expenditure shares in Table 3, the compensations required for males to achieve their within-household utility levels when they come to live alone are generally higher than the compensations required for females. Similarly to before, this reflects the unequal sharing of consumption within households (which was also captured by the sharing rule). However, the differences between the male and female money metric indices in Table 4 are not exactly the same as the differences between the male and female expenditure shares in Table 3. Intuitively, in terms of our structural model of collective household consumption, these discrepancies follow from diverging individual preferences for publicly consumed quantities.

\begin{tabular}{|l|cc|cc|}
\hline & \multicolumn{2}{|c|}{ men } & \multicolumn{2}{c|}{ women } \\
\hline percentile & $\mathrm{m}_{E}^{1, l b}$ & $\mathrm{~m}_{E}^{1, u b}$ & $\mathrm{~m}_{E}^{2, l b}$ & $\mathrm{~m}_{E}^{2, u b}$ \\
\hline 10 & $52,895.3$ & $69,890.8$ & $43,251.8$ & $63,479.4$ \\
20 & $69,541.5$ & $82,515.9$ & 56,974 & $77,481.9$ \\
30 & $83,638.5$ & $95,415.5$ & $71,217.5$ & $89,660.5$ \\
40 & 96,506 & 105,755 & $81,567.8$ & 100,327 \\
50 & 108,569 & 118,185 & $97,669.7$ & 112,620 \\
60 & 122,383 & 132,816 & 111,427 & 126,840 \\
70 & 138,957 & 151,361 & 128,192 & 146,763 \\
80 & 173,670 & 190,340 & 154,572 & 174,757 \\
90 & 220,701 & 243,533 & 207,386 & 229,784 \\
\hline
\end{tabular}

Table 4: Bounds on money metric welfare indices

By using the results that are summarized in Table 4, we can analyze households' scale economies that follow from public consumption. Following again our conservative procedure, we obtain a lower bound estimate of households' gains by subtracting the current household income $(y)$ from the sum of the nonparametrically estimated lower bounds on the individuals' money metric welfare indices $\left(m_{E}^{1, l b}+m_{E}^{2, l b}\right)$. Figure 1 presents the distribution of these differences across our sample of households. We obtain non-positive differences for about one quarter of the households. For these households, the current income does not exceed the sum of our estimated lower bounds on the individual $M M W I_{E}^{i}$ 
and, therefore, we cannot reject the hypothesis that there are no gains from public consumption. However, and more interestingly, for a large majority of our households, our conservative procedure does reveal strictly positive gains, again showing the informative value of our nonparametric identification method. As a matter of fact, for about one half of the households we learn that the gains from living together amounts to at least 10,000 dollars, which represents a significant fraction of the expenditures on the Hicksian public good for a modal household (see Table 1).

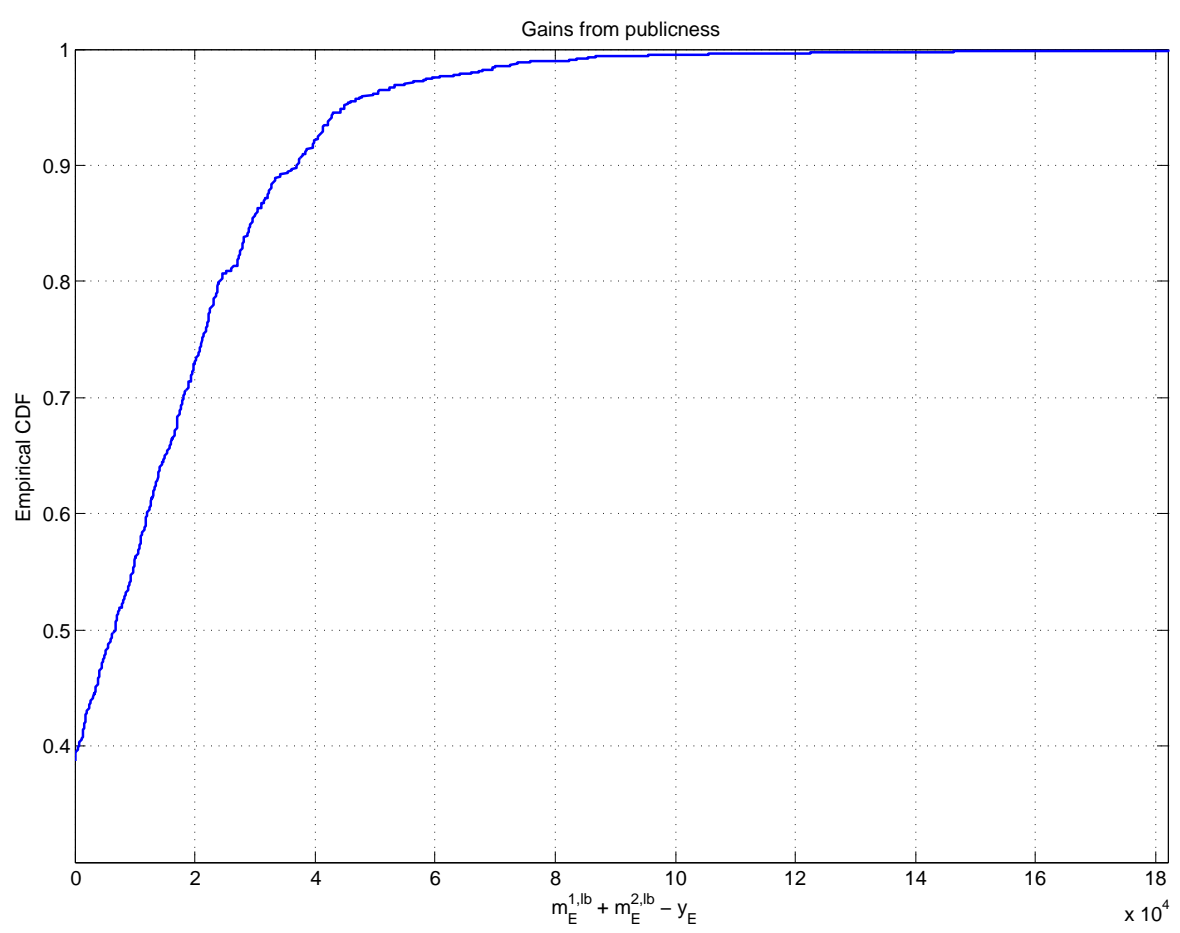

Figure 1: Gains from public consumption

As a further comparison, we relate our estimation results for the individual money metric indices to the Slutsky compensation measures $s_{E}^{i}=w_{E}^{i} l_{E}^{i}+Q_{E}$. To recall, money metric welfare indices can be conceived as Hicksian compensation measures because they incorporate behavioral reactions to price changes (i.e. from Lindahl prices for public consumption when living together to prices of unity when living alone). These behavioral effects are ignored by the Slutsky compensation measures.

To assess the empirical importance of these behavioral aspects, we compare the results in Table 4 with those in Table 5. Interestingly the upper bounds $m_{E}^{i, u b}$ of our Hicksian measure are always (slightly) smaller than the Slutsky measures. This confirms once more that our procedure results in significantly tight bounds. Next, the pronounced differences between the Slutsky measures $s_{E}^{i}$ and the lower bounds $m_{E}^{i, l b}$ indicate a substantial potential relevance of accounting for behavioral effects when assessing the welfare impact of price changes associated with becoming single. 


\begin{tabular}{|l|cc|}
\hline & men & women \\
\hline percentile & $\mathrm{s}_{E}^{1}$ & $\mathrm{~s}_{E}^{2}$ \\
\hline 10 & $70,090.1$ & $64,496.3$ \\
20 & $82,637.2$ & $78,281.4$ \\
30 & $96,314.1$ & $90,235.1$ \\
40 & 106,069 & 101,023 \\
50 & 118,868 & 114,240 \\
60 & 133,175 & 127,205 \\
70 & 153,515 & 146,926 \\
80 & 190,340 & 177,788 \\
90 & 243,932 & 230,178 \\
\hline
\end{tabular}

Table 5: Slutsky compensation

Money metric welfare, total income and relative wages. The results of the above identification analyses can be used to address a variety of empirical questions that specifically relate to the intrahousehold distribution of consumption. For example, they allow one to analyze the effects of household characteristics like income and relative wages on individual consumption shares. ${ }^{11}$ A specific feature of our method is that we can now also address these questions for money metric welfare indices.

Panel (a) of Figure 2 shows the relationship between the female money metric welfare indices, which we here express as proportions of the households' full incomes, and the logarithms of these households' full incomes. Each dot and plus sign on the figure represents the upper and lower bound for a given household in our sample. To help visualize the results, we include trendlines of the estimated upper and lower bounds.

The trendlines are slightly decreasing, but quite close to horizontal. This finding suggests that the female's money metric index (as a proportion of the household's full income) does not vary with total income. The trendlines in Figure 2 show that the average upper bounds are steadily around 55-65 percent and the average lower bounds around 45-50 percent. However, the figure also shows considerable heterogeneity across households. For example, some households have upper and lower bounds of the female money metric utility index around 90 percent, whereas other households have bounds around 10 percent.

Let us then compare these results to the ones of Cherchye, De Rock, Lewbel, and Vermeulen (2015), which are based on the sharing rule. These authors find that, on average, the female's (relative) income share is largely independent to the household's

\footnotetext{
${ }^{11}$ These relationships received considerable attention in the literature on collective consumption models. It is frequently assumed in the empirical literature that bargaining power is independent of total household income. See, for example, Lewbel and Pendakur (2008), Bargain and Donni (2012) and Dunbar, Lewbel, and Pendakur (2013), who use this assumption to obtain point identification for resource shares. Next, the literature also provided systematic evidence that a household member's bargaining power generally increases with her/his wage. See, for example, Chiappori, Fortin, and Lacroix (2002), Blundell, Chiappori, Magnac, and Meghir (2007) and Oreffice (2011).
} 
full income. Based on panel (a) of Figure 2, we can add that this independence conclusion also holds when using money metric welfare indices instead of the sharing rule. Next, a notable difference between our results and the ones of Cherchye, De Rock, Lewbel and Vermeulen is that these authors find that the average female income share is situated between 40 percent (lower bound) and 50 percent (upper bound), whereas our average money metric indices are between 45-50 and 55-60 percent of the households' full incomes. Intuitively, this difference can be explained by the fact that the money metric indices take account of scale economies for public consumption, as we dicussed above. Of course, given the different welfare-economic interpretation of the alternative concepts, these differences do not necessarily tell us much more.

Next, Panel (b) of Figure 2 shows the relationship between the female (relative) money metric indices and the relative wages. We clearly observe that a woman's money metric welfare index, as a proportion of the household's full income, generally increases when her relative wage goes up. Again, this conclusion concurs with that of the literature. It supports the argument that a household member's bargaining power generally increases with her/his wage, which results in higher individual welfare.

Individual poverty analysis. To conclude, our estimates allow us to conduct a poverty analysis directly at the level of individuals in households rather than at the level of aggregate households. By using the money metric indices, such a poverty analysis can simultaneously account for both economies of scale in consumption (through public goods) and within-household sharing patterns (reflecting individuals' bargaining positions). To clearly expose the impact of these two mechanisms, we perform three different exercises. In our first exercise, we compute the poverty rate defined in a more standard way, i.e. as the percentage of households having full income that falls below the poverty line, which we fix at 60 percent of the median full income in our sample of households. This also equals the individual poverty rates if there would be equal sharing and no economies of scale. The results of this exercise are given in Table 6 under the heading "Household poverty rate". We would label 11.33 percent of the individuals (and couples) as poor if we ignored scale economies and assumed that household resources are shared equally between males and females.

In a following exercise, we conduct individual poverty analysis on the basis of the sharing rule. Here, we label an individual as poor if his/her income share estimate falls below the individual poverty line, which we define as half of the poverty line for couples that we used above. Based on our sharing rule bounds, we can compute upper and lower bound estimates for the individual poverty rates. The outcomes are summarized under the heading "Sharing rule" in Table 6. Our results indicate that, due to unequal sharing of resources within households, the fraction of individuals living below the poverty line may be considerably greater than the fraction obtained by standard measures that ignore 


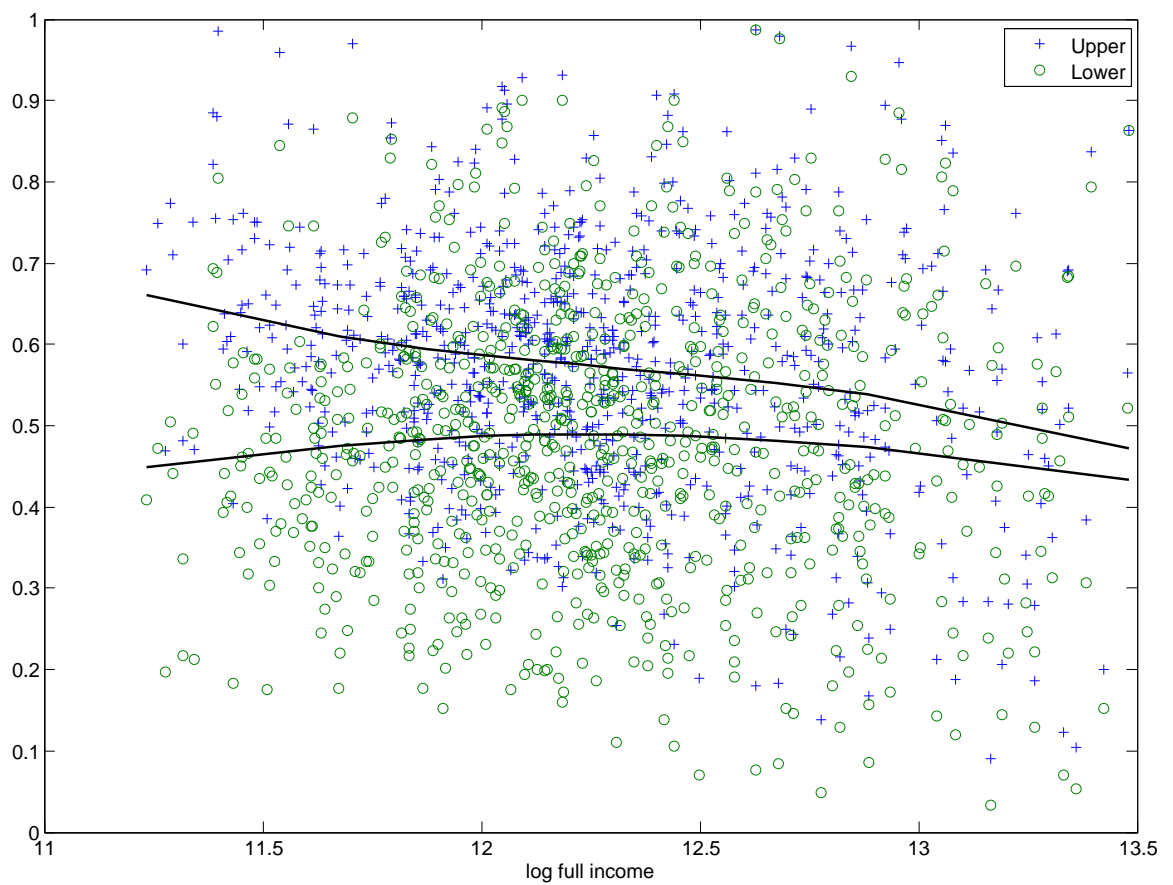

(a) female money metric welfare indices (lower bound $m_{E}^{2, l b}$ and upper bound $m_{E}^{2, u b}$ ) as proportions of the full household income (on vertical axis) versus log of full household income (horizontal axis)

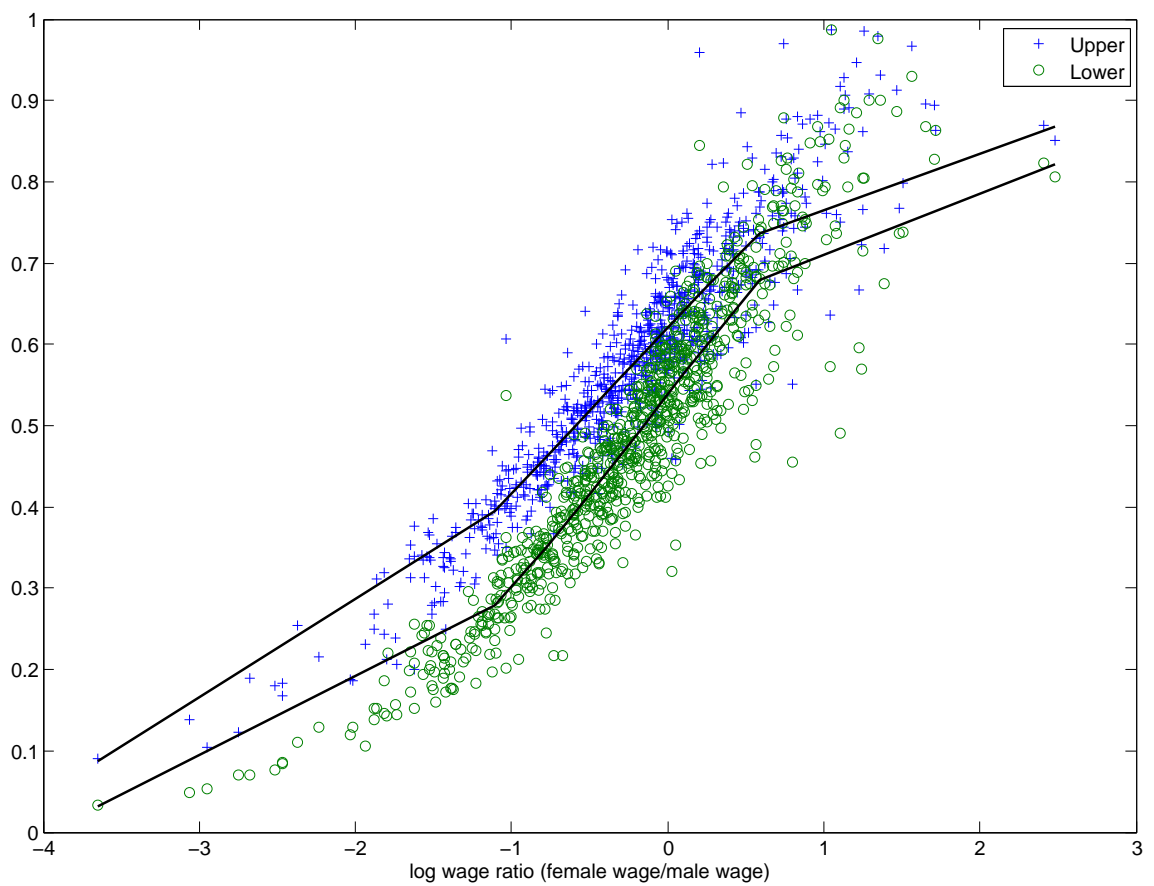

(b) female money metric welfare indices (lower bound $m_{E}^{2, l b}$ and upper bound $m_{E}^{2, u b}$ ) as proportions of the household full household income (on vertical axis) versus log of wage ratio (on horizontal axis)

Figure 2: Female money metric welfare indices, full household income and wage ratio. The lines are trend lines obtained from a local linear fit. 
intrahousehold allocations. In other words, the incidence of poverty at the individual level may be substantially higher than is indicated by standard measures based on household level income. In particular females in households appear to be at risk of poverty because of unequal resource sharing: even the lower bound estimate of female poverty (12.83 percent) is above the individual poverty rate that would occur in the case of equal sharing (11.33 percent, i.e. the household poverty rate).

Finally, we redid the individual poverty analysis (using the same poverty line) but now using the money metric welfare indices as the basis of our calculations. The results of this exercise are reported under the heading "MMWI" in Table 6. We find that both the lower and upper bound estimates of the individual poverty rates decrease when compared to the poverty results based on the sharing rule. Intuitively, the presence of public consumption (giving rise to scale economies) mitigates the risk of poverty. This clearly highlights the importance of households' scale economies in assessing individual poverty. For some households/individuals, publicness of consumption may partly offset the negative effect of unequal sharing and/or different individual Lindahl prices within the household. Our method effectively allows us to disentangle the impact of the two channels.

\begin{tabular}{|cc|cccc|}
\hline & & Households & All individuals & Males & Females \\
\hline Household poverty rate & & $11.33 \%$ & - & - & - \\
\hline \multirow{2}{*}{ Sharing rule } & Upper bound & - & $26.71 \%$ & $22.31 \%$ & $31.10 \%$ \\
& Lower bound & - & $10.69 \%$ & $8.55 \%$ & $12.83 \%$ \\
\hline \multirow{2}{*}{ MMWI } & Upper bound & - & $18.44 \%$ & $14.91 \%$ & $21.97 \%$ \\
& Lower bound & - & $6.24 \%$ & $4.62 \%$ & $7.86 \%$ \\
\hline
\end{tabular}

Table 6: Poverty rates

Figure 3 shows, for the different income deciles, the proportion of households and individual household members considered to be poor. Similar to before, the household poverty rate (panel (a)) is based on the household full income, while the bounds for the individual poverty rates are based on the bounds of the sharing rule (panel (b)) and the money metric welfare indices (panel (c)).

From panel (a) in Figure 3, we learn that the poor (aggregate) households are all situated in the bottom (20\%) of the household income distribution. More revealingly, while households in lower income deciles are typically characterized by a higher degree of individual poverty, from panels (b) and (c) of the figure we also observe that poor individuals are actually situated along the entire income distribution (and even in the top deciles). Once more, this highlights the need to account for unequal resource sharing when evaluating individual poverty. Finally, panel (c) again shows that individual poverty rates (upper and lower bounds) are generally lower when based on money metric welfare indices, which means that we account for intrahousehold scale economies. 


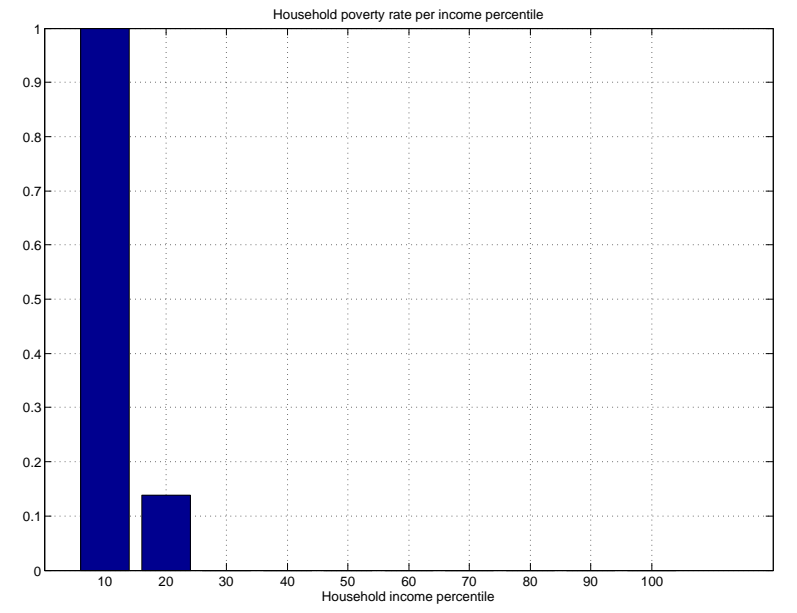

(a) household poverty
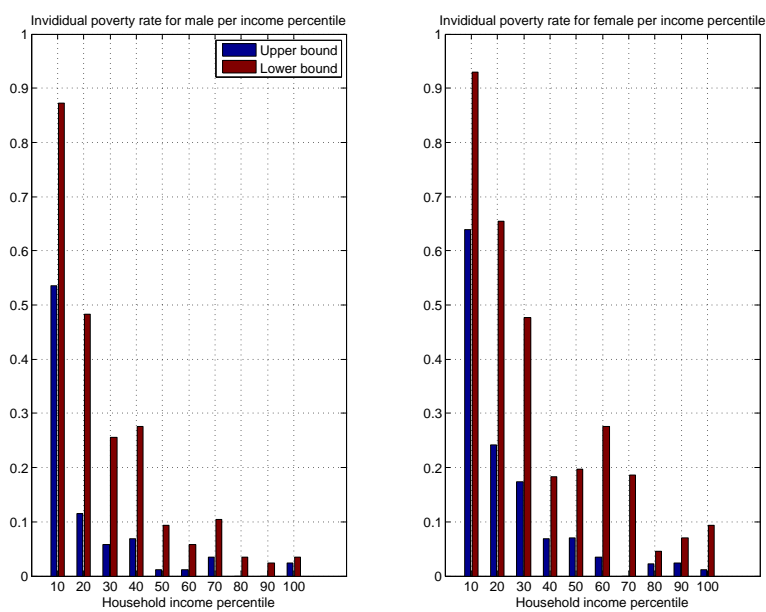

(b) individual poverty based on the sharing rule
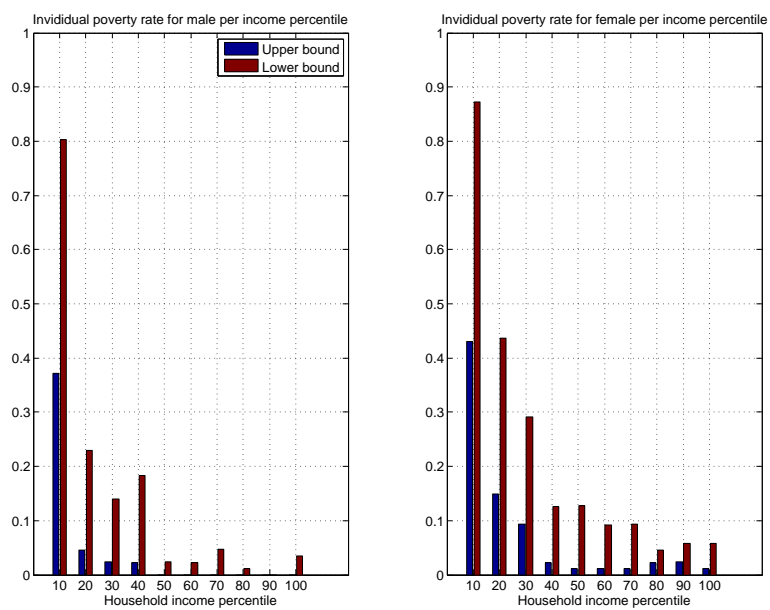

(c) individual poverty based on the money metric welfare indices

Figure 3: Poverty rates at different income percentiles 


\section{Conclusion}

We have presented a novel empirical method to analyze individuals' welfare in a collective consumption setting. Our method allows us to set identify the intrahousehold sharing rule and individual money metric welfare indices from the observed household demand behavior. The method builds on a revealed preference characterization of the collective model that is intrinsically nonparametric. The method can be combined with nonparametric as well as parametric demand estimation. The possibility to conduct a fully nonparametric analysis is particularly attractive, as it yields empirical conclusions that are robust to functional specification error.

We have demonstrated the practical usefulness of our method through a simulation analysis and an empirical application to labor supply data drawn from the Panel Study of Income Dynamics (PSID). We showed that our nonparametric method obtains informative bounds on the intrahousehold distribution of individual resource shares, willingnessto-pay for public consumption (i.e. Lindahl prices) and money metric welfare indices. In addition, our method clearly identified gains from public consumption (i.e. scale economies) associated with living together (versus living alone). Further, we illustrated the usefulness of our method in terms of comparing money metric welfare indices (as Hicksian compensation measures) with Slutsky compensation measures. Such a comparison provides insight into the empirical relevance of accounting for behavioral reactions to price changes associated with becoming single. Finally, we showed the potential of our method to investigate the effects of household characteristics like household income and relative wages on individual welfare, and to assess the incidence of individual (instead of household) poverty evaluated in terms of money metric welfare indices.

\section{References}

Afriat, S. N., 1967. The construction of utility functions from expenditure data. International Economic Review 8, 67-77.

Apps, P., Rees, R., 1988. Taxation and the household. Journal of Public Economics 60, 1999-219.

Attanazio, O., Lechene, V., 2014. Efficient responses to targeted cash transfers. Journal of Political Economy 122, 178-222.

Banks, J., Blundell, R., Lewbel, A., 1997. Quadratic engel curves and consumer demand. The Review of Economics and Statistics 79, 527-539.

Bargain, O., Donni, O., 2012. The measurement of child costs: a Rothbarth-type method 
consistent with scale economies and parents' bargaining. European Economic Review $56,792-813$.

Blundell, R., Browning, M., Crawford, I., 2008. Best nonparametric bounds on demand responses. Econometrica 76, 1227-1262.

Blundell, R., Chiappori, P.-A., Magnac, T., Meghir, C., 2007. Collective labor supply: heterogeneity and nonparticipation. Review of Economic Studies 74, 417-445.

Blundell, R., Chiappori, P.-A., Meghir, C., 2005. Collective labor supply with children. Journal of Political Economy 113, 1277-1306.

Blundell, R., Kristensen, D., Matzkin, R., 2014. Bounding quantile demand functions using revealed preference inequalities. Journal of Econometrics 179, 112-127.

Bourguignon, F., Browning, M., Chiappori, P.-A., 2009. Efficient intrahousehold allocations and distribution factors: implications and identification. Review of Economic Studies 76, 503-528.

Browning, M., Bourguignon, F., Chiappori, P.-A., Lechene, V., 1994. Income and outcomes: a structural model of intrahousehold allocations. Journal of Political Economy 102, 1067-1096.

Browning, M., Chiappori, P.-A., 1998. Efficient intra-household allocations: a general characterization and empirical tests. Econometrica 66, 1241-1278.

Browning, M., Chiappori, P.-A., Lewbel, A., 2013. Estimating consumption economies of scale, adult equivalent scales, and household bargaining power. Review of Economic Studies 80, 1267-1303.

Browning, M., Chiappori, P.-A., Weiss, Y., 2014. Economics of the family. Cambridge University Press.

Browning, M., Goertz, M., 2012. Spending time and money within the household. Scandinavian Journal of Economics 114, 681-704.

Cherchye, L., De Rock, B., Lewbel, A., Vermeulen, F., 2015. Sharing rule identification for general collective consumption models. Econometrica 83 (5), 2001-2041.

Cherchye, L., De Rock, B., Vermeulen, F., 2007. The collective model of household consumption: a nonparametric characterization. Econometrica 75, 553-574.

Cherchye, L., De Rock, B., Vermeulen, F., 2009. Opening the black box of intra-household decision-making: Theory and non-parametric empirical tests of general collective consumption models. Journal of Political Economy 117, 1074-1104. 
Cherchye, L., De Rock, B., Vermeulen, F., 2011. The revealed preference approach to collective consumption behavior: testing and sharing rule recovery. Review of Economic Studies 78, 176-198.

Cherchye, L., De Rock, B., Vermeulen, F., 2012. Married with children: a collective labor supply model with detailed time use and intrahousehold expenditure information. American Economic Review 102, 3377-3405.

Cherchye, L., Vermeulen, F., 2008. Nonparametric analysis of household labor supply: Goodness-of-fit and power of the unitary and the collective model. Review of Economics and Statistics 90, 267-274.

Chiappori, P.-A., 1988. Rational household labor supply. Econometrica 56, 63-90.

Chiappori, P.-A., 1992. Collective labor supply and welfare. Journal of Political Economy $100,437-467$.

Chiappori, P.-A., 2016. Equivalence versus indifference scales. Economic Journal 126, $523-545$.

Chiappori, P.-A., Fortin, B., Lacroix, G., 2002. Marriage market, divore legislation and household labor supply. Journal of Political Economy 110, 37-72.

Chiappori, P.-A., Meghir, C., 2014. Intra-household welfare. NBER Working Paper 20189.

Couprie, H., Peluso, E., Trannoy, A., 2010. Is power more evenly balanced in poor households? Journal of Public Economics 94, 493-507.

Diewert, W. E., 1973. Afriat and revealed preference theory. The Review of Economic Studies 40, 419-425.

Dunbar, G., Lewbel, A., Pendakur, K., 2013. Children's resources in collective households: identification, estimation and an application to child poverty in malawi. American Economic Review 103, 438-471.

Fan, J., Gijbels, I., 1996. Local polynomial modelling and its applications: monographs on statistics and applied probability 66. Vol. 66. CRC Press.

Henry, M., Mourifié, I., 2013. Euclidean revealed preferences: testing the spatial voting model. Journal of Applied Econometrics, 650-666.

Hoderlein, S., Stoye, J., 2014. Revealed preferences in a heterogenous population. Review of Economics and Statistics 96, 197-213.

Houthakker, H., 1950. Revealed preference and the utility function. Economica, 159-174. 
Kaido, H., Molinari, F., Stoye, J., 2016. Confidence intervals for projections of partially identified parameters. Mimeo.

Kitamura, Y., Stoye, J., 2013. Nonparametyric analysis of random utility models. Mimeo.

Lewbel, A., Pendakur, K., 2008. Estimation of collective household models with Engel curves. Journal of Econometrics, 350-358.

Lise, J., Seitz, S., 2011. Consumption inequality and intra-household allocations. Review of Economic Studies 78, 328-355.

Oreffice, S., 2011. Sexual orientation and household decision making: same-sex couples, balance of power and labor supply choices. Labour Economics 18, 145-158.

Smeulders, B., Cherchye, L., De Rock, B., Spieksma, F., Talla Nobibon, F., 2015. Transitive preferences in multi-member households. Economic Theory Bulletin 3, 243-254.

Varian, H. R., 1982. The nonparametric approach to demand analysis. Econometrica 50, $945-974$.

\section{A Proofs}

Proof of Proposition 3. We will focus on $\theta_{E}^{i, u b}$, but a readily similar argument holds for $\theta_{E}^{i, l b}$. If the linear program presented in Section 3 has an infeasible region, then $\theta_{E}^{i, u b}$ is set equal to one and there is nothing to prove. So let us assume that the program is feasible and, thus, the following conditions hold simultaneously for $\theta_{E}^{i, u b}$ :

$$
\begin{aligned}
w_{E}^{i}\left(l_{n}^{i}-l_{E}^{i}\right)+\left(\theta_{E}^{i, u b}+\delta\right)\left(Q_{n}-Q_{E}\right) & <0 \\
w_{n}^{i}\left(l_{E}^{i}-l_{n}^{i}\right) & <0 \\
w_{n}^{i}\left(l_{E}^{i}-l_{n}^{i}\right)+\left(Q_{E}-Q_{n}\right) & <0
\end{aligned}
$$

which means that $\theta_{E}^{i, u b}+\delta$ is not consistent with the WARP condition (1) in the main text. As an implication, it does not sustain collective rationality and, therefore, $\theta_{E}^{i, u b}+\delta \notin \Phi_{E}^{i}$.

Given the second inequality (which implies $l_{E}^{i}<l_{n}^{i}$ ), we learn from the first inequality that $\left(Q_{n}-Q_{E}\right)<0$. This implies that the above inequalities also hold for any $\tilde{\theta}$ above $\theta_{E}^{i, u b}+\delta$, i.e. $\tilde{\theta} \notin \Phi_{E}^{i}$ for $\tilde{\theta} \geq \theta_{E}^{i, u b}+\delta$. Thus, $\theta_{E}^{i, u b}$ effectively constitutes an upper bound on the shadow prices sustaining collective rationality that are contained in $\Phi_{E}^{i}$.

Proof of Proposition 4. To obtain the wanted conclusion (i.e. $\left.I B^{i}\left(l_{E}^{i}, Q_{E}\right) \subseteq B^{i}\left(l_{E}^{i}, Q_{E}\right)\right)$, we need to show $\left(l_{n}^{i}, Q_{n}\right) \in B^{i}\left(l_{E}^{i}, Q_{E}\right)$ for any $\left(l_{n}^{i}, Q_{n}\right) \in I B^{i}\left(l_{E}^{i}, Q_{E}\right)$. 
As a first step, $\left(l_{n}^{i}, Q_{n}\right) \in I B^{i}\left(l_{E}^{i}, Q_{E}\right)$ implies

$$
\left(Q_{n}-Q_{E}\right) \leq 0 \text { and } w_{n}^{i}\left(l_{n}^{i}-l_{E}^{i}\right)+\theta_{n}^{i, u b}\left(Q_{n}-Q_{E}\right) \geq 0 .
$$

Because $\theta_{n}^{i, u b} \geq \theta_{n}^{i}$ for any $\theta_{n}^{i} \in \Theta_{n}^{i}$, these two inequalities imply $w_{n}^{i}\left(l_{n}^{i}-l_{E}^{i}\right)+\theta_{n}^{i}\left(Q_{n}-\right.$ $\left.Q_{E}\right) \geq 0$ for any $\theta_{n}^{i} \in \Theta_{n}^{i}$.

Next, because $\Phi_{E}^{i} \subseteq \Theta_{n}^{i}$, we thus have $w_{n}^{i}\left(l_{n}^{i}-l_{E}^{i}\right)+\bar{\theta}_{n}^{i}\left(Q_{n}-Q_{E}\right) \geq 0$ for any shadow price $\bar{\theta}_{n}^{i} \in \Phi_{E}^{i}$ that sustains collective rationality (following Proposition 3). Then, using a basic (WARP-based) revealed preference argument (see, for example, Varian (1982)), this last inequality implies $U^{i}\left(l_{n}^{i}, Q_{n}\right) \geq U^{i}\left(l_{E}^{i}, Q_{E}\right)$ or, equivalently, $\left(l_{n}^{i}, Q_{n}\right) \in B^{i}\left(l_{E}^{i}, Q_{E}\right)$.

Proof of Proposition 5. Suppose that $\left(l^{i}, Q\right) \notin O B^{i}\left(l_{E}^{i}, Q_{E}\right)$. This implies that there exists $n \in N$ such that

$$
\begin{aligned}
w_{E}^{i}\left(l_{E}^{i}-l_{n}^{i}\right)+\theta_{E}^{i, l b}\left(Q_{E}-Q_{n}\right) \geq & 0 \text { if } Q_{n}<Q_{E}, \text { or } \\
w_{E}^{i}\left(l_{E}^{i}-l_{n}^{i}\right)+\theta_{E}^{i, u b}\left(Q_{E}-Q_{n}\right) \geq & 0 \text { if } Q_{n} \geq Q_{E}, \\
& \text { and } \\
w_{n}^{i}\left(l_{n}^{i}-l^{i}\right)+\theta_{n}^{i, l b}\left(Q_{n}-Q\right) & >0 .
\end{aligned}
$$

From the first two inequalities, we can conclude that $U^{i}\left(l_{E}^{i}, Q_{E}\right) \geq U^{i}\left(l_{n}^{i}, Q_{n}\right)$ for the given $n$. Like in our proof of Proposition 4, this last result follows from a basic (WARP-based) revealed preference argument (see, for example, Varian (1982)) and using $\Phi_{E}^{i} \subseteq \Theta_{E}^{i}$ (following Proposition 3, for $\Phi_{E}^{i}$ containing the shadow prices that sustain collective rationality).

In what follows, we will consider two cases: $Q_{n} \geq Q$ and $Q_{n}<Q$. For each case, we will obtain that $\left(l^{i}, Q\right) \notin\left\{\left(l^{i \prime}, Q^{\prime}\right) \in B^{i}\left(l_{E}^{i}, Q_{E}\right) \mid Q^{\prime} \leq Q_{E}\right\}$, which gives the wanted conclusion (i.e. $\left.\left\{\left(l^{i}, Q\right) \in B^{i}\left(l_{E}^{i}, Q_{E}\right) \mid Q \leq Q_{E}\right\} \subseteq O B^{i}\left(l_{E}^{i}, Q_{E}\right)\right)$.

We begin by considering $Q_{n} \geq Q$. Then, from the above constraints, the inequality $w_{n}^{i}\left(l_{n}^{i}-l^{i}\right)+\theta_{n}^{i}\left(Q_{n}-Q\right)>0$ holds for any $\theta_{n}^{i} \in \Theta_{n}^{i}$. Given this, a similar revealed preference argument as above yields $U^{i}\left(l_{n}^{i}, Q_{n}\right)>U^{i}\left(l^{i}, Q\right)$. Thus, $U^{i}\left(l_{E}^{i}, Q_{E}^{i}\right)>U^{i}\left(l^{i}, Q\right)$, which gives $\left(l^{i}, Q\right) \notin B^{i}\left(l_{E}^{i}, Q_{E}\right)$.

Next, we turn to $Q_{n}<Q$. For $l_{E}^{i}>l^{i}$, when using that we need only consider $Q \leq Q_{E}$, a directly similar argument as before obtains $\left(l^{i}, Q\right) \notin B^{i}\left(l_{E}^{i}, Q_{E}\right)$.

Thus, the only situation left to consider is $Q_{n}<Q$ and $l_{E}^{i} \leq l^{i}$. If $w_{E}^{i}\left(l_{E}^{i}-l^{i}\right)+$ $\theta_{E}^{i, l b}\left(Q_{E}-Q\right)>0$, the same argument as before implies $U^{i}\left(l_{E}^{i}, Q_{E}^{i}\right)>U^{i}\left(l^{i}, Q\right)$ and, thus, $\left(l^{i}, Q\right) \notin B^{i}\left(l_{E}^{i}, Q_{E}\right)$.

As a final step, we show that we can exclude $w_{E}^{i}\left(l_{E}^{i}-l^{i}\right)+\theta_{E}^{i, l b}\left(Q_{E}-Q\right) \leq 0$ for $Q_{n}<Q$ and $l_{E}^{i} \leq l^{i}$. To see this, we first note that, because $w_{n}^{i}\left(l_{n}^{i}-l^{i}\right)+\theta_{n}^{i, l b}\left(Q_{n}-Q\right)>0$ and $Q_{n}<Q$, we must have $l_{n}^{i}>l^{i}$. Because $l^{i} \geq l_{E}^{i}$, this implies $\left(l_{n}^{i}-l_{E}^{i}\right)>0$. Next, for 
$U^{i}\left(l_{E}^{i}, Q_{E}\right) \geq U^{i}\left(l_{n}^{i}, Q_{n}\right)$, collective rationality requires $\theta_{n}^{i, l b}\left(Q_{E}-Q_{n}\right)+w_{n}^{i}\left(l_{E}^{i}-l_{n}^{i}\right) \geq 0$. Using $\left(l_{n}^{i}-l_{E}^{i}\right)>0$, we can rephrase this as

$$
\frac{Q_{E}-Q_{n}}{l_{n}^{i}-l_{E}^{i}} \geq \frac{w_{n}^{i}}{\theta_{n}^{i, l b}}
$$

Then, $w_{n}^{i}\left(l_{n}^{i}-l^{i}\right)+\theta_{n}^{i, l b}\left(Q_{n}-Q\right)>0$ implies $Q<Q_{n}+\frac{w_{n}^{i}}{\theta_{n}^{i, l b}}\left(l_{n}^{i}-l^{i}\right)$. Using the above inequality, we can rewrite this as

$$
Q<Q_{n}\left(\frac{l^{i}-l_{E}^{i}}{l_{n}^{i}-l_{E}^{i}}\right)+\frac{Q_{E}}{l_{n}^{i}-l_{E}^{i}}\left(l_{n}^{i}-l^{i}\right) .
$$

In turn, because $w_{E}^{i}\left(l_{E}^{i}-l_{n}^{i}\right)+\theta_{E}^{i, l b}\left(Q_{E}-Q_{n}\right) \geq 0$ implies $Q_{n} \leq\left(\frac{w_{E}^{i}\left(l_{E}^{i}-l_{n}^{i}\right)}{\theta_{E}^{i, l b}}+Q_{E}\right)$, we must have

$$
Q<\left(\frac{w_{E}^{i}\left(l_{E}^{i}-l_{n}^{i}\right)}{\theta_{E}^{i, l b}}+Q_{E}\right)\left(\frac{l^{i}-l_{E}^{i}}{l_{n}^{i}-l_{E}^{i}}\right)+\frac{Q_{E}}{l_{n}^{i}-l_{E}^{i}}\left(l_{n}^{i}-l^{i}\right) .
$$

Rearranging obtains

$$
0<w_{E}^{i}\left(l_{E}^{i}-l^{i}\right)+\theta_{E}^{i, l b}\left(Q_{E}-Q\right)
$$

which effectively excludes $w_{E}^{i}\left(l_{E}^{i}-l^{i}\right)+\theta_{E}^{i, l b}\left(Q_{E}-Q\right) \leq 0$.

\section{B Additional empirical results}

To show the versatility of our method, and to assess robustness of our main empirical results, we also combine our identification method with Banks, Blundell, and Lewbel (1997)'s Quadratic Almost Ideal Demand System (QUAIDS). This demand system was also used by Cherchye, De Rock, Lewbel, and Vermeulen (2015), and we refer to that paper for a detailed explanation of the QUAIDS system that we use here. In line with Cherchye et al. (2015), we consider QUAIDS estimates with and without accounting for taste shifters (in casu, age of the husband and a dummy for home ownership). Our QUAIDS parameter estimates are available upon request.

As explained in Section 6, a difference between our set-up and the original set-up of Cherchye, De Rock, Lewbel and Vermeulen is that we consider only three goods (i.e. leisure of the two spouses and Hicksian (public) consumption) instead of five goods, which makes that our empirical results are not directly comparable. Next, the fact that we focus on a three-goods setting also makes that, in contrast to Cherchye, De Rock, Lewbel and Vermeulen, we cannot impose the SR1 condition of Browning and Chiappori (1998) in our QUAIDS estimation. The reason is that this SR1 condition only has empirical bite if there are at least 5 goods.

The QUAIDS-based sharing rule bounds are summarized in Table 7. Like Table 
2 , it reports on the percentage point differences between upper and lower bounds on individual expenditure shares for our sample of households. When comparing Tables 2 and 7, we find that the nonparametric kernel-based bounds are close to the QUAIDSbased bounds, which indicates that our parametric QUAIDS model yields results similar to the nonparametric demand system.

As a further comparison, Figures 4 and 5 present the width of the kernel-based and QUAIDS-based sharing rule bounds (in absolute terms). Each dot represents a household. The improved width is on the vertical axis and the naive width on the horizontal axis. Interestingly, the width of the sharing rule bounds is reduced by (more than) half for a significant number of households. In line with our above conclusion, the kernel-based and QUAIDS-based results are very similar.

\begin{tabular}{|l|cc|}
\hline & QUAIDS & QUAIDS with taste shifters \\
\hline mean & 11.35 & 11.03 \\
minimum & 2.55 & 2.54 \\
1st quartile & 7.82 & 7.47 \\
median & 10.27 & 10.02 \\
3rd quartile & 14.27 & 13.59 \\
maximum & 36.69 & 36.61 \\
& & 865 \\
nr. obs. & 865 & \\
\hline
\end{tabular}

Table 7: Percentage point differences between upper and lower bounds on individual female expenditure shares

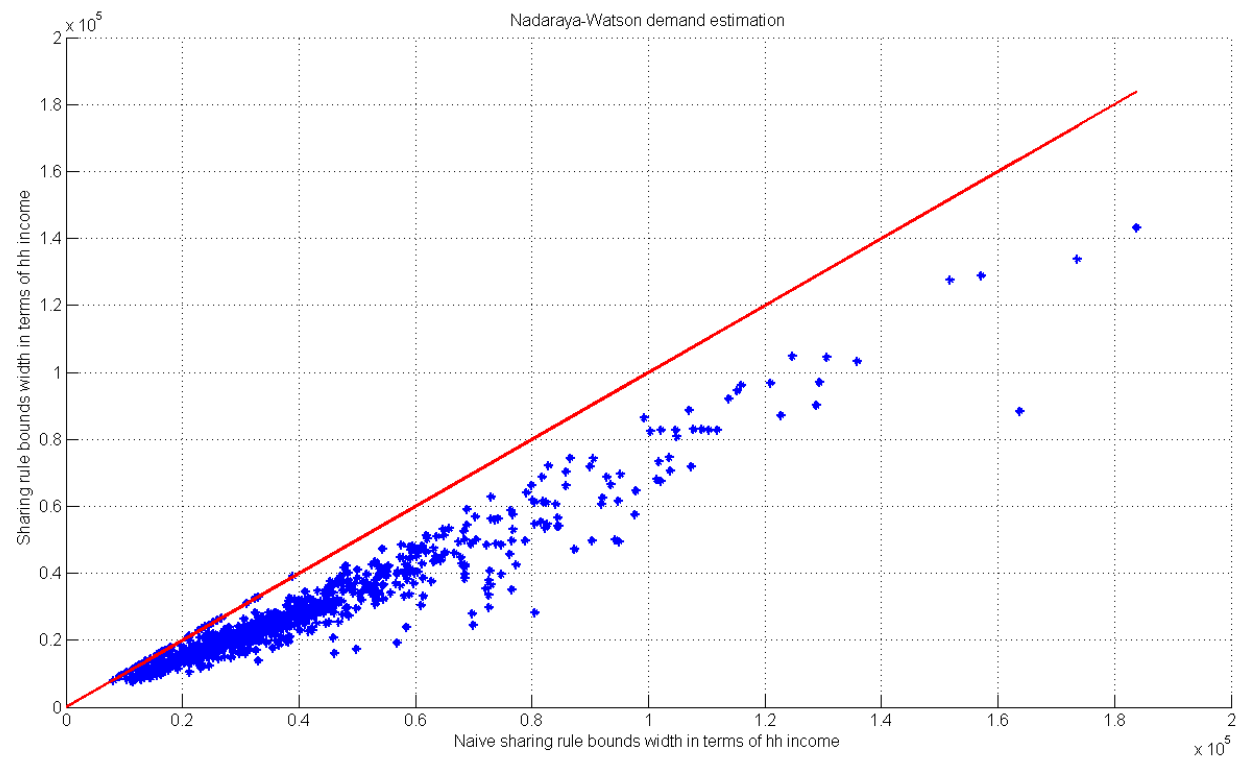

Figure 4: Width of sharing rule bounds in absolute terms (red line = naive bounds) (kernel-based) 


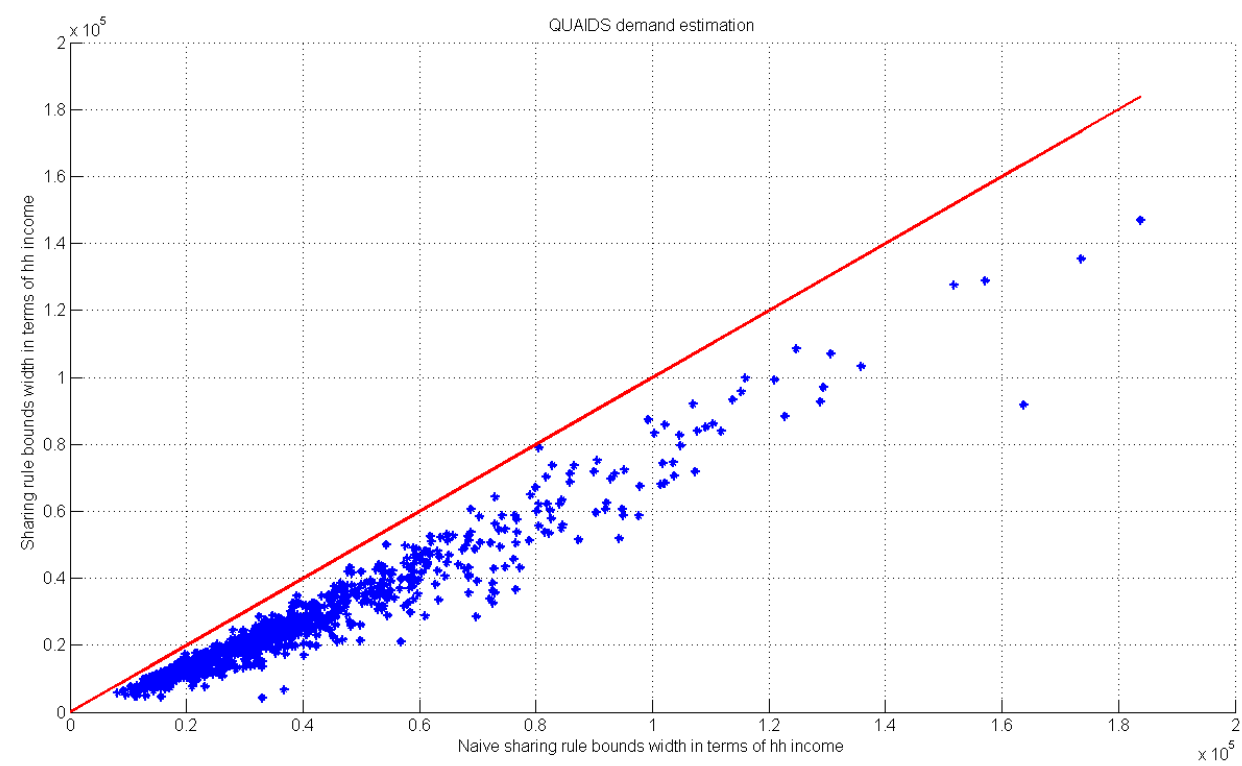

Figure 5: Width of sharing rule bounds in absolute terms (red line = naive bounds) (QUAIDS-based)

Finally, Tables 8, 9 and 10 have a directly similar interpretation as the kernel-based Tables 3, 4 and 5 in the main text, but are QUAIDS-based (with and without taste shifters). Once more, the QUAIDS-based analyses are very similar to the kernel-based results in the main text. 


\begin{tabular}{|c|c|c|c|c|}
\hline \multicolumn{5}{|c|}{ QUAIDS } \\
\hline & \multicolumn{2}{|c|}{ men } & \multicolumn{2}{|c|}{ women } \\
\hline percentile & lower bound & upper bound & lower bound & upper bound \\
\hline 10 & $48,127.2$ & $63,699.1$ & $39,258.9$ & $53,740.7$ \\
\hline 20 & $59,933.3$ & $78,409.1$ & $52,245.6$ & $67,917.3$ \\
\hline 30 & $71,456.7$ & $90,138.4$ & $60,967.2$ & $79,410.5$ \\
\hline 40 & $79,292.6$ & $99,530.9$ & $69,947.8$ & $91,104.5$ \\
\hline 50 & $89,734.6$ & 113,807 & $82,192.7$ & 107,976 \\
\hline 60 & 103,793 & 129,365 & $93,999.6$ & 120,538 \\
\hline 70 & 119,860 & 151,887 & 107,820 & 138,630 \\
\hline 80 & 148,920 & 183,349 & 134,324 & 172,328 \\
\hline 90 & 195,916 & 244,404 & 172,092 & 221,465 \\
\hline \multicolumn{5}{|c|}{ QUAIDS with taste shifters } \\
\hline & \multicolumn{2}{|c|}{ men } & \multicolumn{2}{|c|}{ women } \\
\hline percentile & lower bound & upper bound & lower bound & upper bound \\
\hline 10 & $48,065.9$ & $62,590.8$ & $39,415.9$ & $53,923.2$ \\
\hline 20 & $59,850.1$ & $76,985.6$ & $53,013.4$ & $67,913.6$ \\
\hline 30 & $71,555.3$ & $88,620.5$ & $61,436.7$ & $79,558.5$ \\
\hline 40 & 79,304 & $99,369.7$ & $70,085.3$ & $91,254.5$ \\
\hline 50 & $90,223.5$ & 113,528 & $82,793.9$ & 107,611 \\
\hline 60 & 103,539 & 130,136 & $94,739.6$ & 120,127 \\
\hline 70 & 120,159 & 151,442 & 107,582 & 138,357 \\
\hline 80 & 149,019 & 183,164 & 134,659 & 172,221 \\
\hline 90 & 195,891 & 244,331 & 171,372 & 221,493 \\
\hline
\end{tabular}

Table 8: Sharing rule bounds 


\begin{tabular}{|c|c|c|c|c|}
\hline \multicolumn{5}{|c|}{ QUAIDS } \\
\hline & \multicolumn{2}{|c|}{ men } & \multicolumn{2}{|c|}{ women } \\
\hline percentile & $\mathrm{m}_{E}^{1, l b}$ & $\mathrm{~m}_{E}^{1, u b}$ & $\mathrm{~m}_{E}^{2, l b}$ & $\mathrm{~m}_{E}^{2, u b}$ \\
\hline 10 & $57,866.7$ & $67,204.5$ & $41,192.2$ & $60,832.9$ \\
\hline 20 & $74,983.4$ & $82,650.8$ & $55,874.9$ & $75,505.5$ \\
\hline 30 & $86,557.7$ & $94,561.7$ & $67,554.7$ & $88,240.5$ \\
\hline 40 & $97,474.5$ & 104,772 & $77,208.6$ & $98,075.9$ \\
\hline 50 & 108,503 & 117,949 & $91,258.5$ & 113,365 \\
\hline 60 & 122,881 & 135,949 & 104,105 & 127,954 \\
\hline 70 & 140,977 & 154,790 & 121,206 & 143,848 \\
\hline 80 & 173,473 & 188,494 & 152,268 & 177,347 \\
\hline 90 & 224,826 & 246,064 & 199,745 & 223,227 \\
\hline \multicolumn{5}{|c|}{ QUAIDS with taste shifters } \\
\hline & \multicolumn{2}{|c|}{ men } & \multicolumn{2}{|c|}{ women } \\
\hline percentile & $\mathrm{m}_{E}^{1, l b}$ & $\mathrm{~m}_{E}^{1, u b}$ & $\mathrm{~m}_{E}^{2, l b}$ & $\mathrm{~m}_{E}^{2, u b}$ \\
\hline 10 & $56,820.7$ & $65,082.6$ & $42,185.1$ & $57,418.7$ \\
\hline 20 & $72,988.3$ & 80,004 & $55,455.9$ & $70,841.8$ \\
\hline 30 & $84,717.7$ & 90,896 & $67,619.4$ & $83,612.9$ \\
\hline 40 & $96,075.3$ & 101,555 & $76,738.2$ & $94,335.6$ \\
\hline 50 & 106,164 & 114,491 & 90,677 & 109,169 \\
\hline 60 & 120,662 & 131,311 & 103,578 & 123,526 \\
\hline 70 & 139,229 & 150,138 & 120,500 & 138,481 \\
\hline 80 & 170,960 & 180,885 & 150,672 & 171,849 \\
\hline 90 & 221,360 & 239,860 & 198,239 & 218,258 \\
\hline
\end{tabular}

Table 9: Bounds on money metric welfare indices 


\begin{tabular}{|c|c|c|}
\hline \multicolumn{3}{|c|}{ QUAIDS } \\
\hline & men & women \\
\hline percentile & $\mathrm{s}_{E}^{1}$ & $\mathrm{~s}_{E}^{2}$ \\
\hline 10 & $68,835.8$ & $64,689.1$ \\
\hline 20 & $84,207.8$ & $77,617.8$ \\
\hline 30 & $95,638.2$ & $89,735.5$ \\
\hline 40 & 106,652 & $99,313.6$ \\
\hline 50 & 119,381 & 115,479 \\
\hline 60 & 136,169 & 129,620 \\
\hline 70 & 156,479 & 144,671 \\
\hline 80 & 189,752 & 178,319 \\
\hline 90 & 246,655 & 223,432 \\
\hline \multicolumn{3}{|c|}{ QUAIDS with taste shifters } \\
\hline & men & women \\
\hline percentile & $\mathrm{s}_{E}^{1}$ & $\mathrm{~s}_{E}^{2}$ \\
\hline 10 & $67,369.1$ & $62,176.8$ \\
\hline 20 & $81,218.8$ & $75,026.2$ \\
\hline 30 & $93,104.8$ & $87,209.4$ \\
\hline 40 & 103,489 & $96,124.9$ \\
\hline 50 & 116,206 & 111,945 \\
\hline 60 & 132,225 & 125,627 \\
\hline 70 & 151,605 & 139,672 \\
\hline 80 & 183,776 & 173,198 \\
\hline 90 & 240,360 & 218,274 \\
\hline
\end{tabular}

Table 10: Slutsky compensation 
Copyright (c) 2017 @ the author(s). Discussion papers are in draft form. This discussion paper is distributed for purposes of comment and discussion only. It may not be reproduced without permission of the copyright holder. Copies of working papers are available from the author. 